\title{
Laminin Expression in Adult and Developing Retinae: Evidence of Two Novel CNS Laminins
}

\author{
Richard T. Libby, ${ }^{1}$ Marie-France Champliaud, ${ }^{2}$ Thomas Claudepierre, ${ }^{1,2}$ Yin Xu, ${ }^{3}$ Erin P. Gibbons, ${ }^{1}$ \\ Manuel Koch, ${ }^{2}$ Robert E. Burgeson, ${ }^{2}$ Dale D. Hunter, ${ }^{3}$ and William J. Brunken ${ }^{1,2}$ \\ ${ }^{1}$ Department of Biology, Boston College, Chestnut Hill, Massachusetts 02467, ${ }^{2}$ Cutaneous Biology Research Center, \\ Massachusetts General Hospital, Harvard Medical School, Charlestown, Massachusetts 02129, and ${ }^{3}$ Departments of \\ Neuroscience, Anatomy and Cell Biology, and Ophthalmology, Tufts University School of Medicine, Boston, \\ Massachusetts 02111
}

\begin{abstract}
Components of the extracellular matrix exert myriad effects on tissues throughout the body. In particular, the laminins, a family of heterotrimeric extracellular glycoproteins, have been shown to affect tissue development and integrity in such diverse organs as the kidney, lung, skin, and nervous system. Of these, we have focused on the roles that laminins play in the differentiation and maintenance of the nervous system. Here, we examine the expression of all known laminin chains within one component of the CNS, the retina. We find seven laminin chains- $\alpha 3, \alpha 4, \alpha 5, \beta 2$, $\beta 3, \gamma 2$, and $\gamma 3$-outside the retinal basement membranes. Anatomically, these chains are coexpressed in one or both of two locations: the matrix surrounding photoreceptors and the first synaptic layer where photoreceptors synapse with retinal interneurons. Biochemically, four of these chains are coisolated from
\end{abstract}

retinal extracts in two independent complexes, confirming that two novel heterotrimers- $\alpha 4 \beta 2 \gamma 3$ and $\alpha 5 \beta 2 \gamma 3$-are present in the retinal matrix. During development, all four of these chains, along with components of laminin 5 (the $\alpha 3, \beta 3$, and $\gamma 2$ chains) are also expressed at sites at which they could exert important effects on photoreceptor development. Together, these data suggest the existence of two novel laminin heterotrimers in the CNS, which we term here laminin 14 (composed of the $\alpha 4, \beta 2$, and $\gamma 3$ chains) and laminin 15 (composed of the $\alpha 5, \beta 2$, and $\gamma 3$ chains), and lead us to hypothesize that these laminins, along with laminin 5, may play roles in photoreceptor production, stability, and synaptic organization.

Key words: retina; synapse; matrix; photoreceptor; interphotoreceptor matrix; laminin
The laminins are heterotrimeric glycoproteins of the extracellular matrix, each composed of an $\alpha$, a $\beta$, and a $\gamma$ chain (Burgeson et al., 1994). Currently, 11 laminin chains have been identified: five $\alpha$, three $\beta$, and three $\gamma$ chains (for review, see Timpl, 1996; Koch et al., 1999). Although the exact combinations of chains that can combine to form heterotrimers are unknown, it has been suggested that there are at least 12 distinct laminin heterotrimers (Timpl, 1996; Miner et al., 1997; Koch et al., 1999), termed laminins 1-12.

Defects in several of the component chains have been shown to cause disease in humans. Mutations in the $\alpha 2$ chain have been linked to a muscular dystrophy that is also marked by CNS demyelination (for review, see Arahata et al., 1995); defects in all three chains of laminin $5(\alpha 3, \beta 3$, and $\gamma 2)$ have been linked to a degenerative skin disorder, junctional epidermolysis bullosa (for review, see Timpl, 1996); a muscular dystrophy (Walker-Warburg syndrome) that also has ocular involvement shows reduced expression of the $\beta 2$ chain (Wewer et al., 1995); and finally, the gene encoding $\gamma 3$ maps to the site of a wide variety of neurodevelopmental disorders that include eye-brain-muscle disease and retinitis pigmentosa 21 (Koch et al., 1999). Targeted mutations of laminin genes also support critical roles for laminins during development (for review, see Ryan et al., 1996).

Expression of laminins has been studied in several areas of the

\footnotetext{
Received April 19, 2000; revised June 7, 2000; accepted June 14, 2000.
}

This work was supported, in part, by grants from the Foundation Fighting Blindness and the E. Matilda Ziegler Foundation to W.J.B. and from the National Eye Institute to D.D.H. and by unrestricted funds from Boston College and Tufts University. Some of this work was supported by the core facilities of the Cutaneous Biology Research Center under the Massachusetts General Hospital/Shiseido Co. Ltd. Agreement. We thank Jeff Miner and Josh Sanes for their gifts of the antibodies to the laminin $\alpha 4$ and $\alpha 5$ chains and Yoshi Yamada for antibodies to the laminin $\gamma 2$ chain.

Correspondence should be addressed to Dr. Dale D. Hunter, Department of Neuroscience SC-6, Tufts University School of Medicine, 136 Harrison Avenue, Boston, MA 02111. E-mail: dhunter_neu@opal.tufts.edu.

Dr. Libby's present address: Medical Research Council Institute of Hearing Research, Nottingham NG7 2RD, United Kingdom.

Copyright (C) 2000 Society for Neuroscience $0270-6474 / 00 / 206517-12 \$ 15.00 / 0$ nervous system; of these, we have focused on the retina. In the inner retina, several groups have associated laminin chains with retinal ganglion cells (Cohen et al., 1987; Sarthy and Fu, 1990; Dong and Chung, 1991; Morissette and Carbonetto, 1995). In the outer retina, we have shown that the laminin $\beta 2$ chain is associated with photoreceptors (Hunter et al., 1992b; Libby et al., 1996). The $\beta 2$ chain promotes the expression of the rod photoreceptor phenotype in vitro (Hunter et al., 1992b; Hunter and Brunken, 1997) and is vital for proper photoreceptor development in vivo (Libby et al., 1999). In the peripheral nervous system, laminins appear to mediate synaptic formation or stability (Hunter et al., 1989; Noakes et al., 1995); within the retina, they may subserve similar functions in the outer plexiform layer (Libby et al., 1999).

The identity of the laminin(s) present in the retina is currently unknown. To define the functional retinal heterotrimers and their roles in retinal development and maintenance, it is important to ascertain with which $\alpha$ and $\gamma$ chain(s) the laminin $\beta 2$ chain is associated. Here, we identify several laminin chains in the interphotoreceptor matrix and plexiform layers, allowing us to hypothesize that two novel laminins containing the laminin $\beta 2$ chainlaminins 14 and 15-exist; we also demonstrate biochemically that these heterotrimers are components of the retinal matrix. These laminins, together with laminin 5, are likely to be important during neuronal maturation and maintenance in the retina and, by extension, the rest of the CNS.

\section{MATERIALS AND METHODS}

Animal and tissue preparation. All procedures involving animals were approved by the Boston College, Massachusetts General Hospital, and Tufts University animal care committees and were in accordance with the National Institutes of Health Guide for the Care and Use of Animals and the policies of the Society for Neuroscience. Rats were killed by exposure to $\mathrm{CO}_{2}$. Human retinal sections, unfixed and fixed, were a gift of Dr. Ann Milam (Scheie Eye Institute, University of Pennsylvania, Philadelphia, PA).

Immunohistochemistry. Immunohistochemistry was performed as described previously (Libby et al., 1996, 1997). Adult rat eyecups were embedded in OCT compound (Miles, Elkhart, IN) and frozen by immer- 
sion in liquid nitrogen-cooled isopentane; transverse, $10-\mu \mathrm{m}$-thick sections were cut with a Leica cryostat and placed onto Superfrost Plus slides (Fisher Scientific, Pittsburgh, PA). Human retina specimens were obtained as unfixed transverse sections. Slides were stored at $-20^{\circ} \mathrm{C}$ until use. For use, slides were returned to room temperature, immersed briefly in acetone (or, interchangeably, for all but the $\alpha 5, \beta 3$, and $\gamma 2$ chains, $\mathrm{MeOH}$ ) at $-20^{\circ} \mathrm{C}$, washed in PBS (137 mM NaCl, $2.68 \mathrm{~mm} \mathrm{KCl}, 10 \mathrm{mM} \mathrm{Na}_{2} \mathrm{HPO}_{4}$, and $1.76 \mathrm{mM} \mathrm{KH}_{2} \mathrm{PO}_{4}$, pH 7.4), and then incubated in primary antibodies for $2 \mathrm{hr}$ at room temperature or overnight at $4^{\circ} \mathrm{C}$. Primary antibodies (see below) were diluted in PBS containing $2 \%$ goat serum, $2 \%$ bovine serum albumin, or both. Sections were washed in PBS and incubated in speciesappropriate, affinity-purified, fluorescently labeled secondary antibodies diluted in $2 \%$ goat serum in PBS for $1 \mathrm{hr}$ at room temperature. After washes in PBS, slides were mounted in $90 \%$ glycerol and $10 \%$ water, containing para-phenylenediamine $(1 \mathrm{mg} / \mathrm{ml}$; Sigma, St. Louis, MO) to reduce photobleaching, or in Prolong (Molecular Probes, Eugene, OR).

The antibodies used were as follows: laminin 1, $\alpha 1 \beta 1 \gamma 1$ [Life Technologies, Gaithersburg, MD; rabbit polyclonal to mouse Engelbreth-HolmSwarm (EHS) tumor protein]; laminin $\alpha 2$ chain (Life Technologies; mouse monoclonal to human protein); laminin $\alpha 3$ chain [BM-2; made in one of our laboratories (R.E.B.); mouse monoclonal to human protein]; laminin $\alpha 4$ chain [Miner et al. (1997); rabbit polyclonal to mouse fusion protein or R17; made in one of our laboratories (R.E.B.); rabbit polyclonal to human fusion protein]; laminin $\alpha 5$ chain (Miner et al. [1995]; rabbit polyclonal to mouse fusion protein or 4C7; Engvall et al. [1986] [see Tiger et al. (1997) for $\alpha 5$ reactivity]; mouse monoclonal to human protein); laminin $\beta 1$ chain [C21; Sanes and Chiu (1983); mouse monoclonal to rat protein]; laminin $\beta 2$ chain [GP1; Sanes et al. (1990a); guinea pig polyclonal to rat fusion protein or C4; Sanes and Chiu (1983); mouse monoclonal to bovine protein or D5; Hunter et al. (1989); mouse monoclonal to bovine protein]; laminin $\beta 3$ chain [6F12; Rouselle et al. (1991); mouse monoclonal to human protein]; laminin $\gamma 1$ chain [D18; Sanes et al. (1990a); mouse monoclonal to rat fusion protein]; laminin $\gamma 2$ chain [Sugiyama et al. (1995); rabbit polyclonal]; laminin $\gamma 3$ chain [R16 and R21; Koch et al. (1999); rabbit polyclonals to human protein and human fusion protein, respectively]; and laminin 5, $\alpha 3 \beta 3 \gamma 2$ [4101; Rouselle et al. (1991); Marinkovich et al. (1992) or 8Ln5 and 9Ln5; made in one of our laboratories (R.E.B.); rabbit polyclonals to human protein]. 8Ln5 and 9Ln5 were made to the same antigen as the published antiserum 4101 and have the same reactivity.

In situ hybridizations. Adult rat eyecups were dissected and fixed overnight at $4^{\circ} \mathrm{C}$ in $4 \%$ paraformaldehyde in $\mathrm{PBS}, \mathrm{pH} 7.4$, dehydrated, and embedded in paraffin. Fifteen-micrometer-thick sections were cut and placed onto Probe-on Plus slides (Fisher Scientific). Human retina specimens were obtained as fixed transverse sections. Rehydrated rat sections or frozen human sections were then processed for in situ hybridizations as described previously (Libby et al., 1997).

cRNA probes for the laminin chains were generated as described previously (Libby et al., 1997). Probes for the laminin $\beta 1$ and $\beta 2$ chains and for cellular retinaldehyde-binding protein were those used previously (Libby et al., 1997). A cRNA probe for the laminin $\alpha 5$ chain (Miner et al., 1995) was generated from a plasmid obtained from J. Sanes (Washington University, Saint Louis, MO). All other laminin chain probes were generated from plasmids (containing fragments of human laminin cDNAs) obtained in one of our laboratories (R.E.B.). cRNAs were labeled during transcription by the incorporation of digoxigenin-UTP (Boehringer Mannheim, Indianapolis, IN); $\sim 1 \mu \mathrm{g} / \mathrm{ml}$ cRNA was used for hybridization.

Biochemical isolation of laminin heterotrimers. Bovine eyes were obtained from Pel-Freeze Biologicals (Rogers, AR) and dissected to isolate the retinae. Approximately 50 retinae were pooled, washed in PBS containing the protease inhibitors phenylmethylsulfonyl fluoride $(150 \mathrm{mg} / \mathrm{l})$ and $N$-ethylmaleimide $(650 \mathrm{mg} / \mathrm{l})$, frozen in liquid nitrogen, ground in a Waring blender, resuspended in $100 \mathrm{ml}$ of $2 \mathrm{M}$ urea, $0.5 \mathrm{M} \mathrm{NaCl}, 10 \mathrm{~mm}$ EDTA, $1 \mathrm{~mm}$ phenylmethylsulfonyl fluoride, $5 \mathrm{~mm}$ N-ethylmaleimide, and $50 \mathrm{~mm}$ Tris- $\mathrm{HCl}, \mathrm{pH} 7.8$, and then stirred for $24 \mathrm{hr}$ at $4^{\circ} \mathrm{C}$. The retinal extract was cleared by centrifugation at $30,000 \times g$ for $60 \mathrm{~min}$, dialyzed in

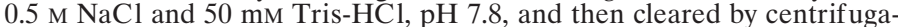
tion at $100,000 \times g$ for $60 \mathrm{~min}$. Glycoproteins were isolated by applying the extract to a concanavalin A-Sepharose column (Pharmacia, Piscataway, $\mathrm{NJ}$ ); unbound material was removed by washing with $0.5 \mathrm{M} \mathrm{NaCl}, 5 \mathrm{~mm}$ $\mathrm{CaCl}_{2}, 5 \mathrm{mM} \mathrm{MgCl}_{2}$, and $50 \mathrm{~mm}$ Tris-HCl, $\mathrm{pH}$ 7.4. The column was washed with $10 \mathrm{mM} \alpha$-D-methylmannopyranoside in $0.5 \mathrm{M} \mathrm{NaCl}$ and $50 \mathrm{~mm}$ Tris-HCl, pH 7.4, and then eluted with $1 \mathrm{M} \alpha$-D-methylglucopyranoside in $0.5 \mathrm{M} \mathrm{NaCl}$ and $50 \mathrm{~mm}$ Tris- $\mathrm{HCl}, \mathrm{pH} 7.4$.

To isolate laminin 14 and laminin 15, the concanavalin A eluate was separated without sulfhydryl reduction on a 3-5\% polyacrylamide-SDS ge (Laemmli, 1970). After staining with Coomassie brilliant blue R-250 (Sigma), bands containing the high-molecular weight proteins were excised, washed in $0.5 \mathrm{M}$ Tris- $\mathrm{HCl}, \mathrm{pH}$ 6.8, and incubated in SDS sample buffer containing $10 \% \beta$-mercaptoethanol for $30 \mathrm{~min}$ at ambient temperature, and the different laminin chains were separated on a $5 \%$ polyacrylamide-SDS gel. Proteins were analyzed by protein transfer (Western) blot analysis (Towbin et al., 1979) using an anti-laminin $\alpha 4$ chain antiserum (R17), an anti-laminin $\beta 2$ chain antibody (D5), and an antilaminin $\gamma 3$ chain antiserum (R21).

The $380 \mathrm{kDa}$ protein isolated by this method was not reactive with any of our anti-laminin antibodies. Therefore, after digestion by the protease
Lys-C, peptide fragments of this protein were sequenced by the use of matrix-assisted laser desorption time-of-flight mass spectrometry (Chait and Kent, 1992) performed on a Finnegan Lasermat 2000 in the Harvard Microchemistry laboratories.

\section{RESULTS}

\section{Protein expression}

Antibodies that recognize the 11 known laminin chains were used to catalog the laminin chains in adult rat and human retinae. We describe here the reactivity for antibodies directed against each of these chains.

\section{Laminin $\alpha$ chains}

A polyclonal antiserum that recognizes the three chains of laminin $1(\alpha 1 \beta 1 \gamma 1)$ reacts only with the vasculature in the rat (Fig. $1 A)$ and human (Fig. $1 B$ ) and not with the matrix of the neural retina itself. Laminin 1 immunoreactivity was seen on the basal side of the retinal pigmented epithelium, that is, Bruch's membrane (Fig. 1A) [Hunter et al. (1992b), compare their Fig. 2E]; in those sections in which the inner limiting membrane is present, laminin 1 is expressed there as well (data not shown). These observations are consistent with numerous other reports (see Kohno et al., 1987; Morissette and Carbonetto, 1995) and suggest that the laminin $\alpha 1$ chain, a component of laminin 1, is not associated with the matrix of either the neural retina or the interphotoreceptor matrix (IPM) but is a component of the basement membranes of the retina: Bruch's membrane and the internal limiting membrane.

The laminin $\alpha 2$ chain, in agreement with a previous report (Morissette and Carbonetto, 1995), is also present in the retinal vasculature (Fig. 1C,D). However, in contrast to this previous report, we did not detect the laminin $\alpha 2$ chain associated with ganglion cell bodies. We have not systematically studied the internal limiting membrane; however, despite the fact that this membrane can be easily removed during isolation of the retina, we regularly had the internal limiting membrane in our sections, and we have not detected the laminin $\alpha 2$ chain associated with this basement membrane. The $\alpha 2$ chain does not appear to be a component of Bruch's membrane.

In contrast, the laminin $\alpha 3$ chain is present in the interphotoreceptor matrix (Fig. $1 E, F$ ); the laminin $\alpha 3$ chain is prominent at the external limiting membrane and at the tips of the photoreceptor inner segments. Laminin $\alpha 3$ chain immunoreactivity is also present in the outer plexiform layer; however, in contrast to the chains of laminin 1 and the laminin $\alpha 2$ chain, which are associated with elements of the vasculature in the outer plexiform layer, the laminin $\alpha 3$ chain does not appear to be associated with the larger vessels in this region. Nevertheless, the laminin $\alpha 3$ chain does appear to be present in the outer plexiform layer; we cannot discern whether the laminin $\alpha 3$ chain is associated with small vessels or associated with the synaptic connections in this layer. In the human, weak immunoreactivity for the laminin $\alpha 3$ chain is also present around cell bodies of the outer and inner nuclear layers (Fig. $1 F$ ). Finally, in the human, the laminin $\alpha 3$ chain is diff usely associated with the inner plexiform layer.

In contrast to the laminin $\alpha 1-\alpha 3$ chains, the laminin $\alpha 4$ chain appears to have a broad distribution in rat and human retinae. Immunoreactivity for the laminin $\alpha 4$ chain is present in the IPM, as well as diffusely in both the inner and outer plexiform layers (Fig. 1G,H). This extensive immunoreactivity in both plexiform layers and the lack of any association with the retinal vasculature suggest that the laminin $\alpha 4$ chain is contained within the extracellular matrix of the plexiform layers. However, the most prominent reactivity for the laminin $\alpha 4$ chain is in what appear to be Müller cell fibers coursing through the retina. These fibers have been confirmed as Müller cell processes, on the basis of colocalization of the laminin $\alpha 4$ chain with a Müller cell marker [vimentin (see Libby et al., 1997)]. Reactivity for the laminin $\alpha 4$ chain is also present in the ganglion cell layer; this may reflect laminin $\alpha 4$ chain associated with the end feet of Müller cells. The presence of the laminin $\alpha 4$ chain within the Müller cell suggests that the Müller 

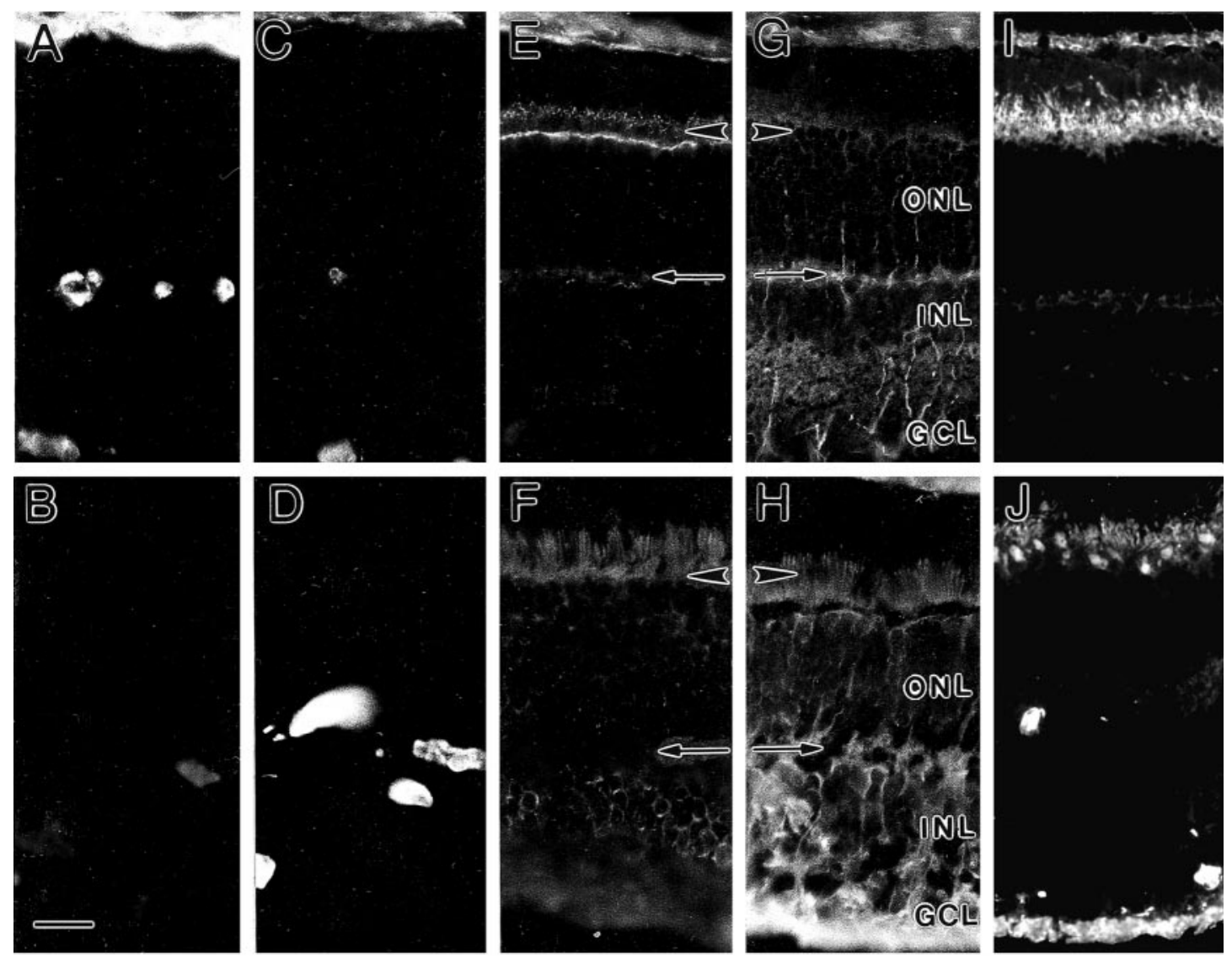

Figure 1. Expression patterns of laminin $\alpha$ chains in mature rat and human retinae. Unfixed frozen sections of rat (top row; $A, C, E, G, I)$ and human (bottom row; $B, D, F, H, J)$ retinae were probed for the presence of the laminins $\alpha 1 \beta 1 \gamma 1(A, B), \alpha 2(C, D), \alpha 3(E, F), \alpha 4(G, H)$, and $\alpha 5(I, J)$ chains by the use of chain-specific (or trimer-specific for $\alpha 1 \beta 1 \gamma 1)$ antibodies. Although several chains are present in the vasculature, only three $(\alpha 3, \alpha 4$, and $\alpha 5)$ are expressed within the interphotoreceptor matrix (arrowheads) and outer plexiform layer (arrows). In addition, $\alpha 4$ is present in fibers extending through the outer nuclear layer $(O N L)$ and inner nuclear layer $(I N L)$. GCL, Ganglion cell layer. Scale bar, $25 \mu \mathrm{m}$.

cell is a source of the laminin $\alpha 4$ chain in the neural retina, consistent with the data that confirmed the Müller cell as a source of another laminin chain, $\beta 2$ (Libby et al., 1997).

Our initial localization studies using a polyclonal antiserum raised against the laminin $\alpha 5$ chain (Miner et al., 1995) suggested that the laminin $\alpha 5$ chain was only a component of the true basement membranes of the retina, that is, the internal limiting membrane, Bruch's membrane, and vascular basement membranes (data not shown). However, a monoclonal antibody [4C7 (Engvall et al., 1986)] that specifically recognizes the laminin $\alpha 5$ chain (Tiger et al., 1997) demonstrates that the laminin $\alpha 5$ chain is more broadly distributed within the neural retina: the laminin $\alpha 5$ chain has a distribution similar to that of the laminin $\alpha 3$ chain (Fig. $1 I, J$ ). Specifically, the laminin $\alpha 5$ chain is present in both rat and human interphotoreceptor matrices, as well as in the outer plexiform layer in the rat. In addition, the laminin $\alpha 5$ chain, like the laminin $\alpha 1$ and $\alpha 2$ chains, is associated with the retinal vasculature; this is particularly notable in the human (Fig. $1 J$ ). Laminin $\alpha 5$ chain immunoreactivity is present in the choroid, the hyaloid vessels, the outer plexiform layer vessels, and the vasculature that extends through the retina from the hyaloid vessels to the outer plexiform layer. This expression in the vasculature is similar to the expression pattern of the laminin $\alpha 5$ chain in the brain (our unpublished observations).

Together, these data suggest that all five laminin $\alpha$ chains are expressed in the retina, but two - the laminin $\alpha 1$ and $\alpha 2$ chainsmay be associated exclusively with the retinal vasculature. Of these, the laminin $\alpha 1$ chain has not been directly associated with the basement membrane of vessels; indeed, protein transfer blots of retinal extracts fail to detect the $\alpha 1$ chain (Hunter et al., 1992b). In the case of the laminin $\alpha 2$ chain, these data conflict somewhat with previous reports of expression in some vertebrates (Morissette and Carbonetto, 1995), although they are consistent with others (Toti et al., 1997) that show that the laminin $\alpha 2$ chain is restricted to the vasculature in the human retina. In contrast to these two laminin $\alpha$ chains, three-the laminin $\alpha 3, \alpha 4$, and $\alpha 5$ chains-are associated with the IPM and, potentially, are associated with the neural retina at synapses in the plexiform layers. Laminins at each of these locations could be provided from the cell that spans the entire thickness of the retina, the Müller cell; the Müller cell is the likely source for at least one other laminin chain, $\beta 2$ (Libby et al., 1997).

\section{Laminin $\beta$ chains}

As noted above, a polyclonal serum that recognizes all three chains of laminin 1 , including the laminin $\beta 1$ chain, reacts only with the vasculature in rat (Fig. $1 A$ ) and human (Fig. $1 B$ ) retinae; for the human, this pattern is consistent with the previously reported expression of laminin 1 (Kohno et al., 1987; Toti et al., 1997). Thus, the laminin $\beta 1$ chain cannot be an element of the matrix of either the IPM or the neural retina. A rat-reactive antibody against the $\beta 1$ chain confirms this observation (Fig. $2 A$ ). However, because there is little authentic laminin $\alpha 1$ chain in the retina and little authentic laminin $\beta 1$ chain in the retinal vasculature of the rat, it is likely that the polyclonal serum against laminin 1 (e.g., Fig. $2 B$ ) is detecting primarily the laminin $\gamma 1$ chain in the vasculature of both rat and human.

As reported previously in the rat (Hunter et al., 1992b; Libby et al., 1997), the laminin $\beta 2$ chain is present in the interphotoreceptor matrix (Fig. $2 C$ ) and appears to be associated with the external limiting membrane. Here, we also demonstrate a similar distribution in the human retina (Fig. $2 D$ ). The laminin $\beta 2$ chain, a known component of brain vasculature (Hunter et al., 1992a), was also 

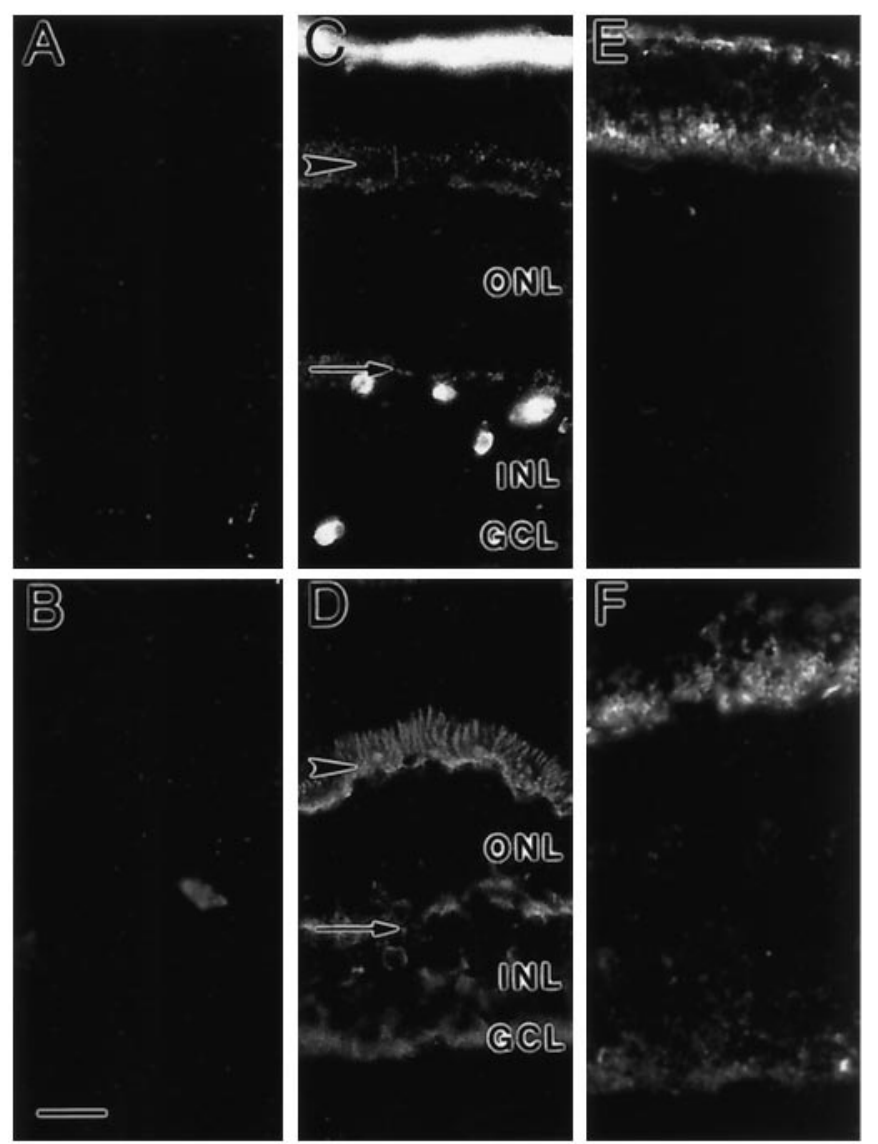

Figure 2. Expression patterns of laminin $\beta$ chains in mature rat and human retinae. Unfixed frozen sections of rat (top row; $A, C, E$ ) and human (bottom row $B, D, F$ ) retinae were probed for the presence of the laminin $\beta 1(A), \alpha 1 \beta 1 \gamma 1(B), \beta 2(C, D)$, and $\beta 3(E, F)$ chains by the use of chain-specific (or trimer-specific for $\alpha 1 \beta 1 \gamma 1$ ) antibodies. Two $\beta$ chains, $\beta 2$ and $\beta 3$, are expressed within the neural retina, specifically, in the interphotoreceptor matrix (arrowheads); in addition, the $\beta 2$ chain is present in the outer plexiform layer (arrows). GCL, Ganglion cell layer; INL, inner nuclear layer; $O N L$, outer nuclear layer. Scale bar, $25 \mu \mathrm{m}$.

associated with the vessels of the retina. In the human, immunoreactivity is also present surrounding cell bodies in the inner nuclear layer, as well as in the inner limiting membrane. In both species, the laminin $\beta 2$ chain is also diffusely associated with the outer plexiform layer. A comparison of this diffuse immunoreactivity with that for laminin 1 or the laminin $\alpha 2$ chain suggests that the laminin $\beta 2$ chain is not only associated with the vasculature within the outer plexiform layer. As was true for the laminin $\alpha 3$ chain, we cannot say conclusively that the laminin $\beta 2$ chain is associated with the extracellular matrix of the outer plexiform layer. However, it is intriguing to speculate that the laminin $\beta 2$ chain may be localized to synapses in the CNS, as it is in the peripheral nervous system (Hunter et al., 1989).

Laminin $\beta 3$ chain immunoreactivity was also present in the mature rat retina (Fig. $2 E$ ), as well as in the mature human retina (Fig. $2 F$ ). The $\beta 3$ chain seems primarily limited to the interphotoreceptor matrix, suggesting that laminins containing the laminin $\beta 3$ chain are components of this matrix. Because laminin $\beta 3$ has a "tightly restricted tissue distribution" in the rodent (Utani et al., 1995) and has, to date, only been demonstrated as a component of laminin $5(\alpha 3 \beta 3 \gamma 2)$, it is likely that this reflects the presence of laminin 5 in the interphotoreceptor matrix.

Together, these data suggest that, although the laminin $\beta 1$ chain is associated with the basement membrane of the retinal vasculature in both rat and human retinae, only two $\beta$ chains - the laminin $\beta 2$ [as reported previously in rat, rabbit, and skate (Hunter et al., $1992 b)]$ and $\beta 3$ chains - are expressed in the matrix of the IPM.
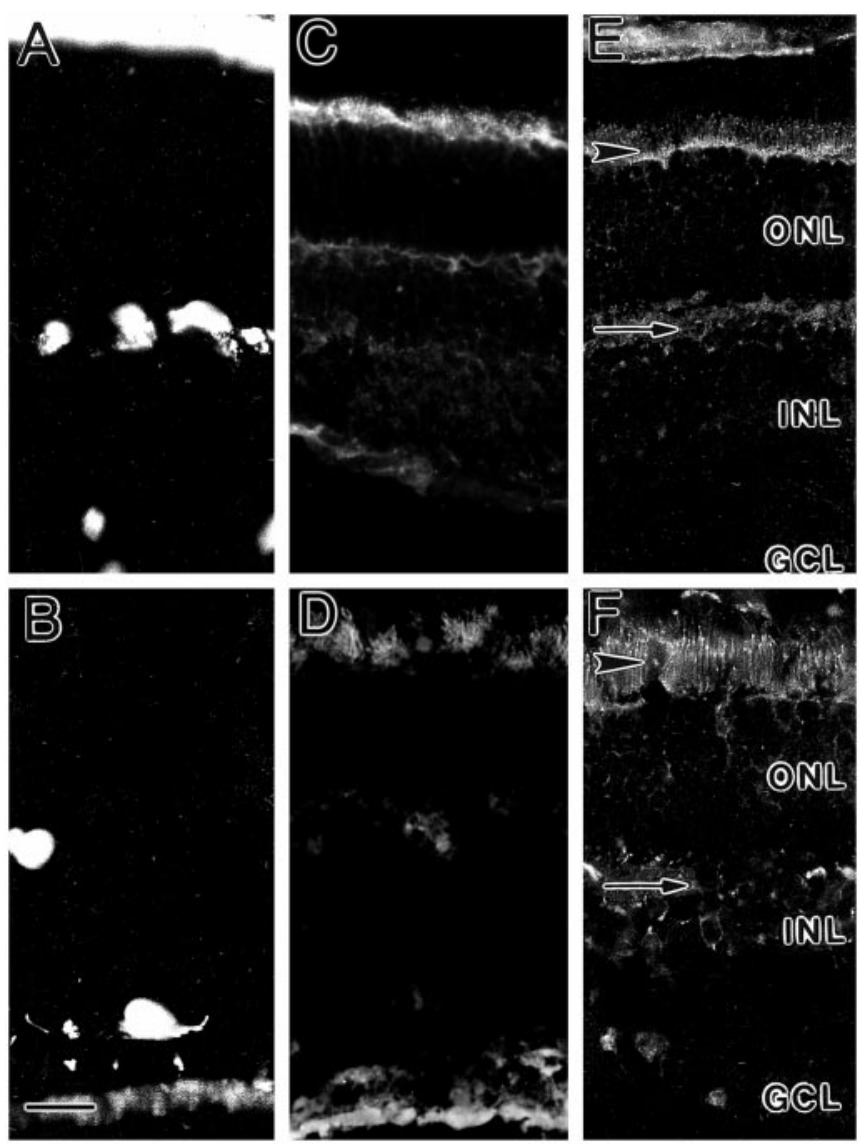

Figure 3. Expression patterns of laminin $\gamma$ chains in mature rat and human retinae. Unfixed frozen sections of rat (top row; $A, C, E$ ) and human (bottom row; $B, D, F)$ retinae were probed for the presence of the laminin $\gamma 1(A, B)$, $\gamma 2(C, D)$, and $\gamma 3(E, F)$ chains by the use of chain-specific antibodies. Two $\gamma$ chains, $\gamma 2$ and $\gamma 3$, are expressed within the neural retina, specifically in the interphotoreceptor matrix (arrowheads); in addition, the $\gamma 3$ chain is present in the outer plexiform layer (arrows). GCL, Ganglion cell layer; $I N L$, inner nuclear layer; $O N L$, outer nuclear layer. Scale bar, $25 \mu \mathrm{m}$.

Moreover, the laminin $\beta 2$ chain is also expressed in the matrix of the outer plexiform layer.

\section{Laminin $\gamma$ chains}

As noted above, a polyclonal serum that recognizes all three chains of laminin 1, including the laminin $\gamma 1$ chain, reacts primarily with the vasculature. Consistent with this observation, an antibody directed against the laminin $\gamma 1$ chain reacts only with the vasculature in both rat (Fig. $3 A$ ) and human (Fig. $3 B$ ), suggesting that the anti-laminin 1 serum is reacting with at least the $\gamma 1$ chain. In addition, in the human, the laminin $\gamma 1$ chain is present at the internal limiting membrane (Fig. $3 B$ ); this may reflect production by astrocytes, the hyaloid blood vessels, and retinal ganglion cells (Sarthy and Fu, 1990; cf. Sarthy, 1993). There is also some punctate immunoreactivity for the laminin $\gamma 1$ chain within the ganglion cell layer. Importantly, there is no laminin $\gamma 1$ chain reactivity in the IPM or plexiform layers; thus, the laminin $\gamma 1$ chain is confined to the vitread side of the retina.

In contrast to the laminin $\gamma 1$ chain, the laminin $\gamma 2$ chain is present in the interphotoreceptor matrix of rat (Fig. 3C) and human (Fig. $3 D$ ) retina. It is also present in the hyaloid vessels and, to a limited extent, the intraretinal capillaries of the human. Some laminin $\gamma 2$ chain is also present in the outer plexiform layer of the rat; this immunoreactivity may reflect capillary-associated laminins. As for the laminin $\beta 3$ chain, previous reports have suggested a restricted distribution of the laminin $\gamma 2$ chain (Kallunki et al., 1992).

The laminin $\gamma 3$ chain is the most recently isolated of the growing 

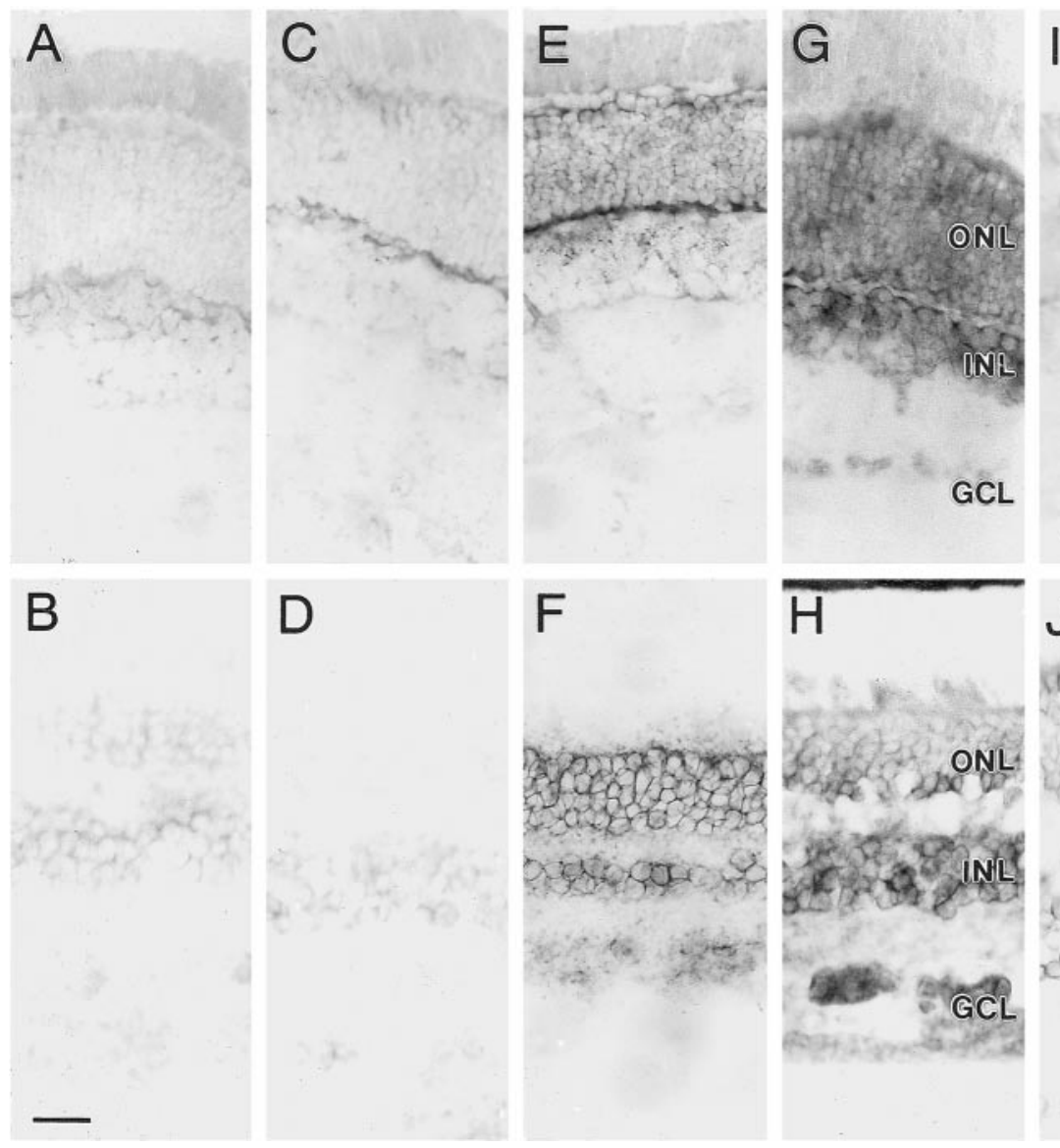
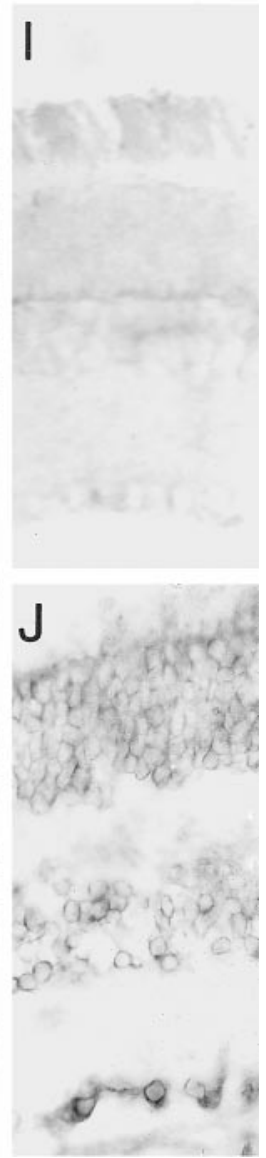

Figure 4. Expression patterns of the RNA encoding laminin $\alpha$ chains in mature rat and human retinae. Fixed sections of rat (top row; $A, C, E, G, I)$ and human (bottom row; $B, D, F, H, J$ ) retinae were probed for the presence of RNA encoding the laminin $\alpha 1(A, B)$, $\alpha 2(C, D), \alpha 3(E, F), \alpha 4(G, H)$, and $\alpha 5$ $(I, J)$ chains by the use of chain-specific cRNA probes. Two RNAs (those encoding $\alpha 3$ and $\alpha 4$ ) are expressed within the neural retina of both species; in addition, the RNA encoding $\alpha 5$ is readily detected in human retina. GCL, Ganglion cell layer; INL, inner nuclear layer; $O N L$, outer nuclear layer. Scale bar, $25 \mu \mathrm{m}$. family of laminins (Koch et al., 1999). The tissue distribution of this chain is quite limited; however, it seems most extensively expressed in the nervous system (our unpublished observations), including the mouse retina (Libby et al., 1999). Here, we document the presence of the laminin $\gamma 3$ chain in a portion of the human and rat CNS. Prominent laminin $\gamma 3$ chain immunoreactivity is present in the interphotoreceptor matrix, notably, throughout the region of photoreceptor inner segments (Fig. $3 E, F$ ). In addition, there is marked laminin $\gamma 3$ chain immunoreactivity associated with the external limiting membrane in the rat (Fig. $3 E$ ) and surrounding cell bodies within the outer and inner nuclear layers in the human (Fig. $3 F$ ). Finally, the laminin $\gamma 3$ chain is diff usely present in the outer plexiform layer, at least in the rat. As with the laminin $\alpha 3, \alpha 4$, and $\beta 2$ chains, we cannot say conclusively that the laminin $\gamma 3$ chain immunoreactivity in the outer plexiform layer is concentrated at points of synaptic contacts in the outer plexiform layer. However, the laminin $\gamma 3$ chain is not associated with the vasculature present at the vitread side of the retina, and its pattern of expression is distinct from that for laminin chains in the vasculature, such as the $\gamma 1$ chain. Therefore, it is probable that the laminin $\gamma 3$ chain in the outer plexiform layer is contained within the matrix of the plexiform layer.

Together, these data suggest that the laminin $\gamma 2$ and $\gamma 3$ chains are the only known laminin $\gamma$ chains in the IPM. Furthermore, the laminin $\gamma 3$ chain appears to be the only laminin $\gamma$ chain found potentially associated with the synaptic regions of the outer plexiform layer in both rat and human.

\section{Summary of protein expression}

In the IPM, we have shown the presence of seven laminin chains: $\alpha 3, \alpha 4, \alpha 5, \beta 2, \beta 3, \gamma 2$, and $\gamma 3$. This is consistent with the presence of one previously isolated laminin, laminin $5(\alpha 3 \beta 3 \gamma 2)$, as well as several novel laminin heterotrimers. If the other chains were to combine, then, potentially, there would be two such novel laminin trimers in the IPM: $\alpha 4 \beta 2 \gamma 3$ and $\alpha 5 \beta 2 \gamma 3$. In the matrix of the outer plexiform layer, these two trimers also appear to be present, because their component chains are present. In contrast, only one laminin chain, $\alpha 4$, is prominent in the matrix of the inner plexiform layer, suggesting that other, uncharacterized, $\beta$ and $\gamma$ chains may be expressed in the retina.

\section{RNA expression}

cRNA probes that recognize the RNAs encoding the 11 known laminin chains were used to catalog these RNAs in the retina and to localize them to particular cell types. Because laminin trimers are assembled before secretion, the RNAs encoding all three chains of any given trimer should be present in the same cell.

\section{Laminin $\alpha$ chains}

RNAs encoding the laminin $\alpha 1$ (Fig. 4A,B) and $\alpha 2$ (Fig. 4C,D) chains were not readily detected in the rat or human retina, suggesting that both of these RNAs are not abundant in the retina. However, for both chains, some RNA was detected in the inner nuclear layer. This may reflect production of these two chains by components of the vasculature.

In contrast, the RNA encoding the laminin $\alpha 3$ chain is readily detectable in the rat and human retina (Fig. $4 E, F$ ). This expression agrees with the high expression levels of the laminin $\alpha 3$ chain in the retina from the human expressed sequence tag database. Interestingly, laminin $\alpha 3$ chain RNA is not localized to perinuclear sites; rather, the RNA is in fibers coursing through the inner and outer nuclear layers and the outer plexiform layer. This location is consistent with production of laminin $\alpha 3$ chain RNA by Müller cells.

The RNA encoding the laminin $\alpha 4$ chain is present in a pattern similar to that encoding the laminin $\alpha 3$ chain: the RNA appears to be located in fibers coursing through the inner and outer nuclear layers (Fig. 4G,H), which are likely to be Müller cell processes. Unlike laminin $\alpha 3$ chain RNA, there does seem to be perinuclear laminin $\alpha 4$ chain RNA in the inner nuclear layer, particularly of the 

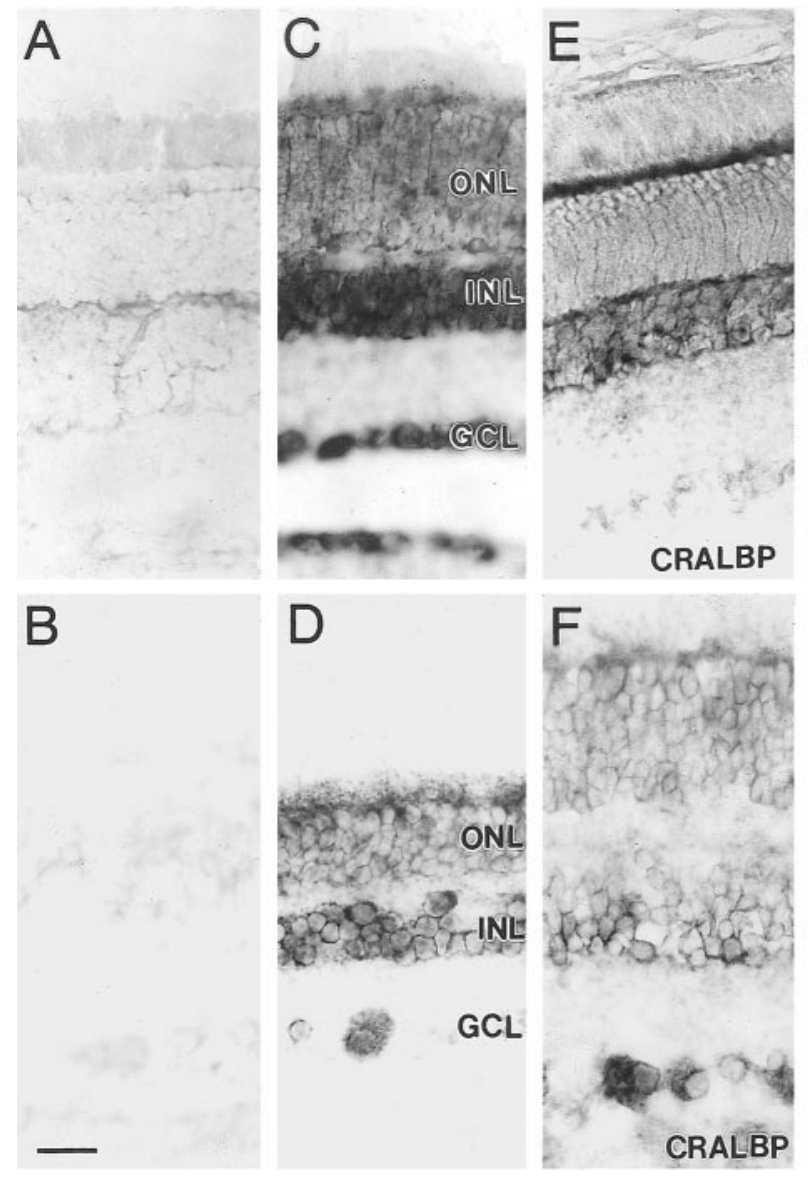

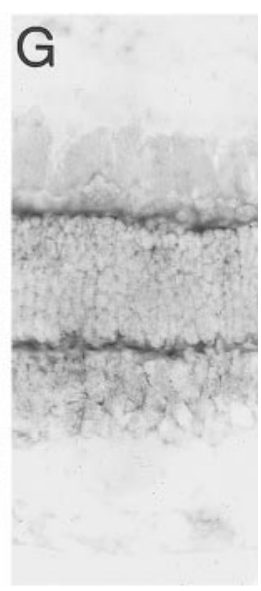

$\mathrm{H}$

Figure 5. Expression patterns of the RNA encoding laminin $\beta$ chains in mature rat and human retinae. Fixed sections of rat (top row; $A, C, E, G$ ) and human (bottom row; $B, D, F, H$ ) retinae were probed for the presence of the RNA encoding laminin $\beta 1(A, B), \beta 2(C, D)$, and $\beta 3(G, H)$ chains by the use of chain-specific cRNA probes. RNA encoding the $\beta 2$ and $\beta 3$ chains is expressed within the neural retina. Expression of an RNA encoding a Müller cell antigen, cellular retinaldehydebinding protein $(C R A L B P)$, is shown for comparison $(E, F)$. $G C L$, Ganglion cell layer; $I N L$, inner nuclear layer; $O N L$, outer nuclear layer. Scale bar, $25 \mu \mathrm{m}$.

human retina (Fig. $4 H$ ), suggesting that the source of the RNA encoding the laminin $\alpha 4$ chain is a cell whose nucleus resides in the inner nuclear layer; Müller cell nuclei are in this layer. Finally, in human, laminin $\alpha 4$ chain RNA is present in the ganglion cell layer, in what we presume to be Müller cell end feet, as we have shown for laminin $\beta 2$ chain RNA (Libby et al., 1997).

Similar to the laminin $\alpha 1$ and $\alpha 2$ chain, RNA encoding the laminin $\alpha 5$ chain is not detectable within the rat retina (Fig. 4I); this suggests that the RNA encoding the laminin $\alpha 5$ chain is not abundant in the rat retina. In an example of species variation, we detected RNA encoding the laminin $\alpha 5$ chain within the neural retina of the human (Fig. $4 J$ ). The pattern of expression for laminin $\alpha 5$ chain RNA in the human retina is similar to, albeit considerably less intense than, that detected with a probe for laminin $\alpha 4$ chain RNA (Fig. 4, compare $H, J$ ).

Together, the patterns of expression of the RNAs encoding the laminin $\alpha$ chains suggest that the laminin $\alpha 3, \alpha 4$, and $\alpha 5$ chain RNAs are expressed in the neural retina, consistent with the presence of laminin $\alpha 3, \alpha 4$, and $\alpha 5$ chain protein noted above. Specifically, they suggest that laminin $\alpha 3, \alpha 4$, and $\alpha 5$ chains are produced in the neural retina and deposited in the matrices of the IPM and outer plexiform layer and, in the case of the laminin $\alpha 4$ chain, the inner plexiform layer.

\section{Laminin $\beta$ chains}

RNA encoding the laminin $\beta 1$ chain is not highly expressed in the neural retina (Fig. 5A,B), as reported previously (Libby et al., 1997). These data are consistent with the lack of laminin $\beta 1$ chain protein in neural structures within the retina.

We have shown previously that the laminin $\beta 2$ chain is expressed in the adult rat retina (Libby et al., 1997). As also shown in Figure $5 C$, RNA encoding the laminin $\beta 2$ chain is present in fibers in the outer and inner nuclear layers of the rat. In the human, RNA encoding the laminin $\beta 2$ chain is present in what appear to be fibers in the inner and outer nuclear layers; it is striking at the external limiting membrane and is also present in the ganglion cell layer (Fig. $5 D$ ). We have ascribed previously the laminin $\beta 2$ chain RNA in the ganglion cell layer to Müller cell end feet (Libby et al., 1997). There is also perinuclear RNA present in and around some cell bodies in the inner nuclear layer, suggesting that a cell in the inner nuclear layer, possibly the Müller cell, is a source of the laminin $\beta 2$ chain in the neural retina. Finally, as shown here (Fig. $5 E$ ) and previously (Libby et al., 1997) for the rat and here for the human (Fig. $5 F$ ), this pattern of RNA expression is similar to that of cellular retinaldehyde-binding protein, an authentic marker of the Müller cell (Bunt-Milam and Saari, 1983).

Laminin $\beta 3$ chain RNA appears to be expressed in the adult rat retina: RNA encoding the laminin $\beta 3$ chain is located in fibers coursing through the inner and outer nuclear layers, in the outer plexiform layer, and at the external limiting membrane (Fig. 5G). In another example of species variation, laminin $\beta 3$ chain RNA could not be detected within the human neural retina (Fig. $5 H$ ).

Together, these data suggest that, in both rat and human, the laminin $\beta 2$ chain is the prominent $\beta$ chain expressed in the neural retina. In addition, the laminin $\beta 3$ chain appears to be a component of the neural retina. Finally, the laminin $\beta 1$ chain is not likely to be expressed in the mature neural retina.

\section{Laminin $\gamma$ chains}

The RNA encoding the laminin $\gamma 1$ chain could not be detected in the neural retina (Fig. $6 A, B$ ). This suggests that the laminin $\gamma 1$ chain protein in the internal limiting membrane is not derived from the neural retina. The laminin $\gamma 1$ chain in the internal limiting membrane must, therefore, be derived from one of the non-neural retinal cells that contact it. Both astrocytes and the hyaloid vessels contact the internal limiting membrane and have been suggested as sources of the protein components of the internal limiting membrane (Sarthy and Fu, 1990; Sarthy, 1993).

RNA encoding the laminin $\gamma 2$ chain was consistently difficult to detect in the retina. However, the RNA is detectable in the inner 


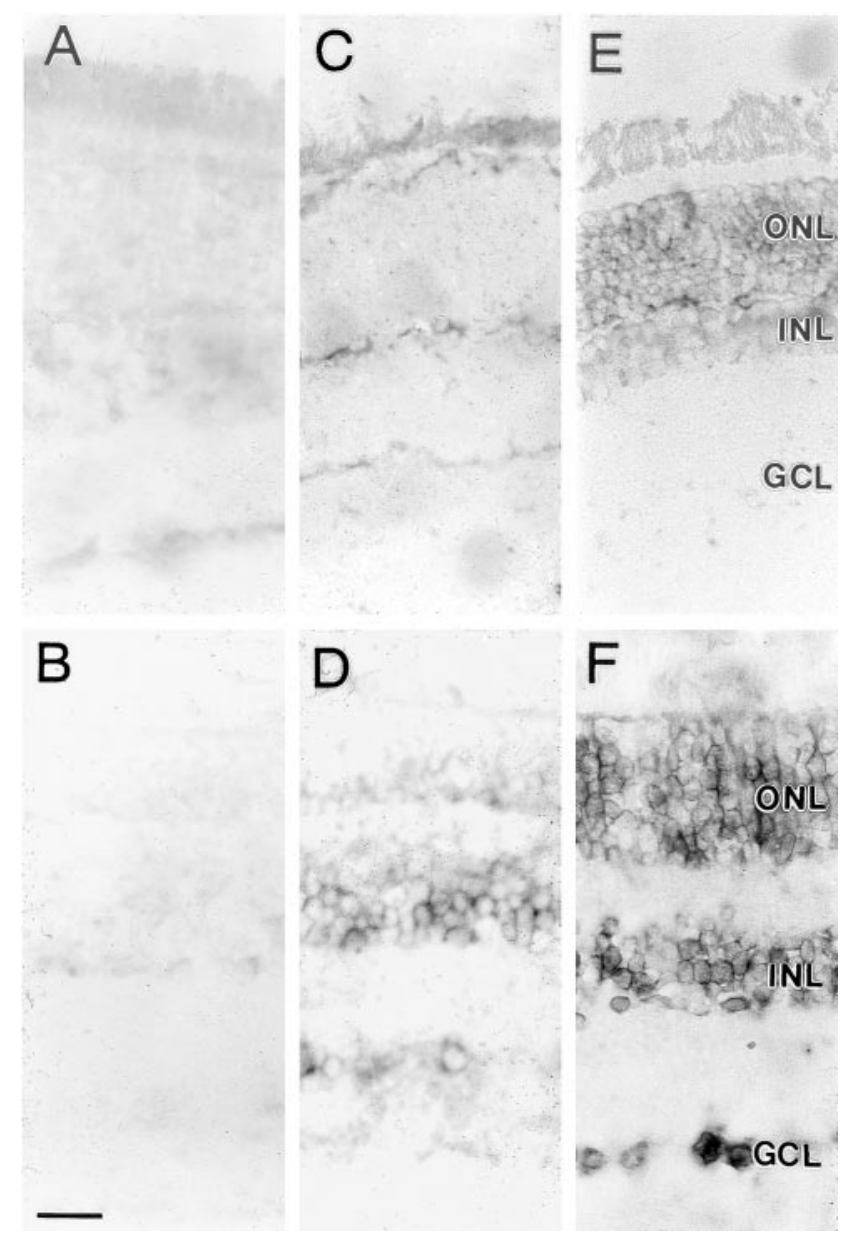

Figure 6. Expression patterns of the RNA encoding laminin $\gamma$ chains in mature rat and human retinae. Fixed sections of rat (top row; $A, C, E$ ) and human (bottom row; $B, D, F$ ) retinae were probed for the presence of the RNA encoding laminin $\gamma 1(A, B), \gamma 2(C, D)$, and $\gamma 3(E, F)$ chains by the use of chain-specific cRNA probes. Only the RNA encoding the $\gamma 3$ chain is readily detected within the neural retina, although $\gamma 2$ can be detected as well. GCL, Ganglion cell layer; INL, inner nuclear layer; $O N L$, outer nuclear layer. Scale bar, $25 \mu \mathrm{m}$.

nuclear layer of the human and, to a lesser extent, the rat retina (Fig. 6C,D).

In contrast, RNA encoding the laminin $\gamma 3$ chain is readily detected in both the rat (Fig. 6E) and human (Fig. 6F) retina. Laminin $\gamma 3$ chain RNA is expressed in a pattern that is similar to that of several other laminin chain RNAs: in fibers coursing through the outer nuclear layer, at the external limiting membrane, and in presumed Müller cell end feet in the ganglion cell layer. The $\gamma 3$ chain is, therefore, a likely $\gamma$ component of mature retinal laminins.

\section{Summary of $R N A$ expression}

The expression patterns of the laminin chain RNAs detected in the neural retina demonstrate that RNAs encoding the laminin $\alpha 3, \alpha 4$, $\beta 2, \gamma 2$, and $\gamma 3$ chains are expressed in the rat and human retina; in addition, RNA encoding the laminin $\alpha 5$ chain was detected in human retina and that encoding the laminin $\beta 3$ chain was detected in rat retina. Although slightly different, the basic distribution of all of these RNAs was the same: primarily within fibers coursing through the inner and outer nuclear layers. RNAs for the laminin $\alpha 4$ and $\beta 2$ chains also appear to be present at perinuclear sites in the inner nuclear layer as well as within the ganglion cell layer. Together, these data suggest that the Müller cell is the source of these laminin chain-encoding RNAs; in addition, they support our assertion that the retina produces two novel laminin trimers: lami$\operatorname{nin} 14(\alpha 4 \beta 2 \gamma 3)$ and laminin $15(\alpha 5 \beta 2 \gamma 3)$.

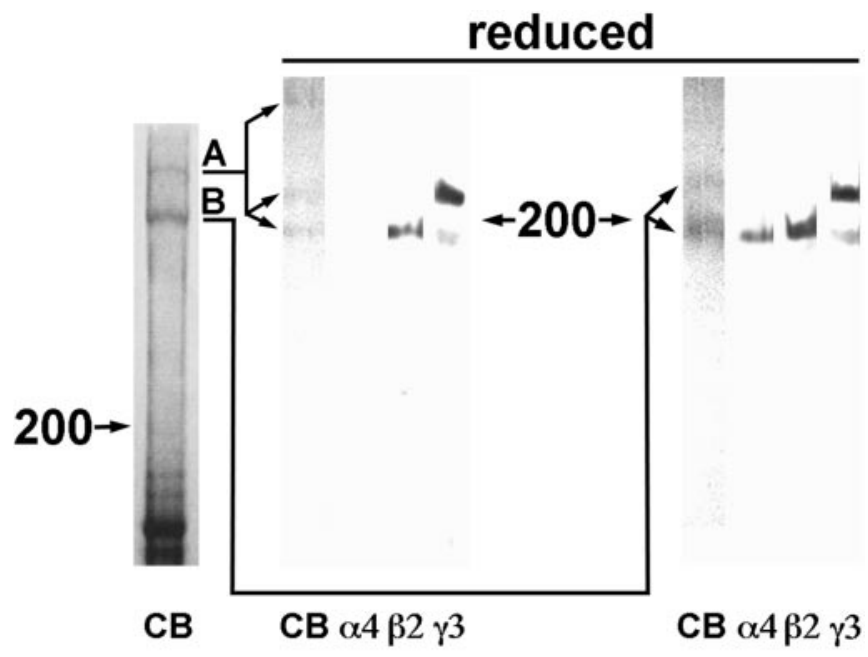

Figure 7. Purification of laminins 14 and 15 from retinal extracts. Glycoproteins were isolated from retinal matrix by concanavalin A chromatography, separated on a nonreducing polyacrylamide gel, and stained with Coomassie blue $(C B)$. Two components $(A, B)$ were further separated on reducing polyacrylamide gels and then probed for the presence of the $\alpha 4$, $\beta 2$, and $\gamma 3$ chains by protein transfer blots. Both $A$ and $B$ contain the $\beta 2$ and $\gamma 3$ chains; $B$ additionally contains the $\alpha 4$ chain. The $\gamma 3$ chain antibody reacts with two bands: the full-length $\gamma 3$ chain and a faster-migrating protein, a degradation product of the $\gamma 3$ chain (or, potentially, crossreactivity with the $\beta 2$ chain) induced by the multiple purification steps used to prepare these proteins. Position of $200 \mathrm{kDa}$ marker is shown.

\section{Biochemical identification of laminin 14 and 15 in the retina}

Our protein and RNA localization data suggest that laminins 5, 14, and 15 are expressed in the neural retina. We have extended these findings by isolating laminins, and their component chains, from the retina.

Although we can demonstrate the presence of the laminin $\alpha 3$ chain protein on protein transfer blots of retinal extracts (data not shown), we have been unable to isolate any heterotrimeric laminins containing the laminin $\alpha 3$ chain from retinal extracts and have, therefore, been unable to confirm biochemically the presence of laminins $5(\alpha 3 \beta 3 \gamma 2)$ or $13(\alpha 3 \beta 2 \gamma 3)$. This may reflect a relative dearth of these trimers in the retina or a difficulty in extracting them in a native form. However, we have shown previously that the laminin $\beta 2$ chain is present in retinal extracts (Hunter et al., $1992 b)$. In addition, laminins eluted from an anti-laminin $\beta 2$ chain resin contain the $\alpha 4$ chain, demonstrating that the $\beta 2$ chain is associated with at least this chain in the retina (data not shown). These studies lead us to ask whether the laminin 14 and 15 trimers are components of the retinal matrix.

Retinal laminins were isolated from retinal matrix by chromatography on concanavalin A-Sepharose followed by size fractionation on polyacrylamide gels. Two high-molecular weight components were selected from this purification scheme (Fig. 7). Each was reduced and separated on polyacrylamide gels. The first (band "A") resolved into components of $\sim 190,220$, and $380 \mathrm{kDa}$ (Fig. 7). Two of these proteins were identified immunologically as the laminin $\beta 2(190 \mathrm{kDa})$ and $\gamma 3(220 \mathrm{kDa})$ chains; the third did not react with any of our anti-laminin antibodies (e.g., anti- $\alpha 4$, Fig. 7). The second high-molecular weight component (band "B") resolved into components of $\sim 190$ and $220 \mathrm{kDa}$. The $190 \mathrm{kDa}$ component consisted of both the $\alpha 4$ and $\beta 2$ chains, and the $220 \mathrm{kDa}$ component was identified as the $\gamma 3$ chain (Fig. 7). No other chains were detected as components of this complex; therefore, band B consists of the novel laminin composed of $\alpha 4, \beta 2$, and $\gamma 3$ chains, which we term laminin 14.

What is the identity of the third component of band A? The high molecular weight of this protein suggested that it was a laminin $\alpha$ chain, perhaps the laminin $\alpha 5$ chain. However, because our antibodies did not react with this protein, it was excised from a 
Table 1. Comparison of sequences of peptide fragments of the $380 \mathrm{kDa}$ component of bovine band $A$ with the deduced amino acid sequence of the mouse laminin $\alpha 5$ chain

\section{Peptide 1}

Mouse laminin $\alpha 5(36-48)^{a}$

Peptide 2

Mouse laminin $\alpha 5$ (53-61)

Peptide 3

Mouse laminin $\alpha 5$ (83-96)

Peptide 4

Mouse laminin $\alpha 5$ (188-198)

Peptide 5

Mouse laminin $\alpha 5$ (797-810)

Peptide 6

Mouse laminin $\alpha 5$ (813-827)

Peptide 7

Mouse laminin $\alpha 5$ (2099-2107)

Peptide 8

Mouse laminin $\alpha 5$ (2640-2646)

Proteolytic fragments of the $380 \mathrm{kDa}$ component of band A (Fig. 7) were sequenced by mass spectrometry. For all eight peptides, the sequence was identical to portions of the deduced amino acid sequence of the mouse laminin $\alpha 5$ chain (Miner et al, 1995), suggesting that the $380 \mathrm{kDa}$ component is the bovine laminin $\alpha 5$ chain.

${ }^{a}$ Amino acids.

polyacrylamide gel, digested, and microsequenced. The resultant fragments were compared with known laminin sequences, and all were identical to sequences within the laminin $\alpha 5$ chain (Table 1), demonstrating that this third component is the laminin $\alpha 5$ chain. Therefore, band B consists of the novel laminin composed of $\alpha 5$, $\beta 2$, and $\gamma 3$ chains, which we term laminin 15 .

\section{Expression of laminins 5, 14, and 15 during retinal development}

We have shown previously that the laminin $\beta 2$ chain is expressed throughout retinal development (Libby et al., 1996, 1997), at first in the subretinal space and subsequently in the interphotoreceptor matrix and the outer plexiform layer. In addition, we have shown recently that the laminin $\beta 2$ chain is critical for the proper formation and function of synapses in the outer plexiform layer (Libby et al., 1999). We have extended these observations by examining the expression of potential partners for the laminin $\beta 2$ chain, that is, components of laminins 14 and 15, during development of the interphotoreceptor matrix and outer plexiform layer. In the course of these experiments, we also found that the components of laminin $5(\alpha 3 \beta 3 \gamma 2)$ are expressed in the developing retina.

We have examined the expression of the components of laminins 14 and 15 as well as those of laminin 5 (the laminin $\alpha 3, \alpha 4, \alpha 5, \beta 2$, $\beta 3, \gamma 2$, and $\gamma 3$ chains) from postnatal day 0 (P0) through P15. We compared the appearance of these chains with that for two components of the photoreceptor synapse, dystrophins and $\beta$-dystroglycan.

At $\mathrm{P} 0$, few rod photoreceptors have differentiated in the rat retina, and the outer plexiform layer has not yet formed (and, therefore, no dystrophins are present; Fig. 8). At this age, the laminin $\beta 2$ chain is prominently expressed in the subretinal space, as we have reported previously at embryonic day 21 (Libby et al., 1996), and in fibers spanning the width of the retina (Fig. 8C), as are the other components of laminins 14 and 15, the laminin $\alpha 4$ (Fig. 8B), $\alpha 5$ (data not shown), and $\gamma 3$ (Fig. 8D) chains. In addition, the laminin $\alpha 3, \beta 3$, and $\gamma 2$ chains are also expressed in these locations, and an antiserum against laminin 5 displays similar immunoreactivity (Fig. $8 H$ ). These immunohistochemical data are consistent with the expression of laminins $14(\alpha 4 \beta 2 \gamma 3), 15$ $(\alpha 5 \beta 2 \gamma 3)$, and $5(\alpha 3 \beta 3 \gamma 2)$ at P0. However, none of the laminin chains is concentrated in the region that will eventually become the outer plexiform layer.

At P5, the central portion of the retina has begun to elaborate an outer plexiform layer in which dystrophins are expressed (Fig. 9A), whereas the peripheral portion has not (Fig. 9B). At this age, the components of laminins 14 and 15 are still present in the subretinal space and in fibers spanning the thickness of the retina (Fig. $9 \mathrm{C}-\mathrm{H}$ ); in addition, in the central portion of the retina, these laminin chains are beginning to be concentrated in the developing outer plexiform layer (Fig. 9C,E,G). Components of laminin 5 remain associated with the subretinal space and in fibers spanning the thickness of the retina (Fig. 9I,J).

At P10, the entire retina has developed an outer plexiform layer in which dystrophins are prominently expressed (Fig. 10A). Interestingly, another component of the adult photoreceptor
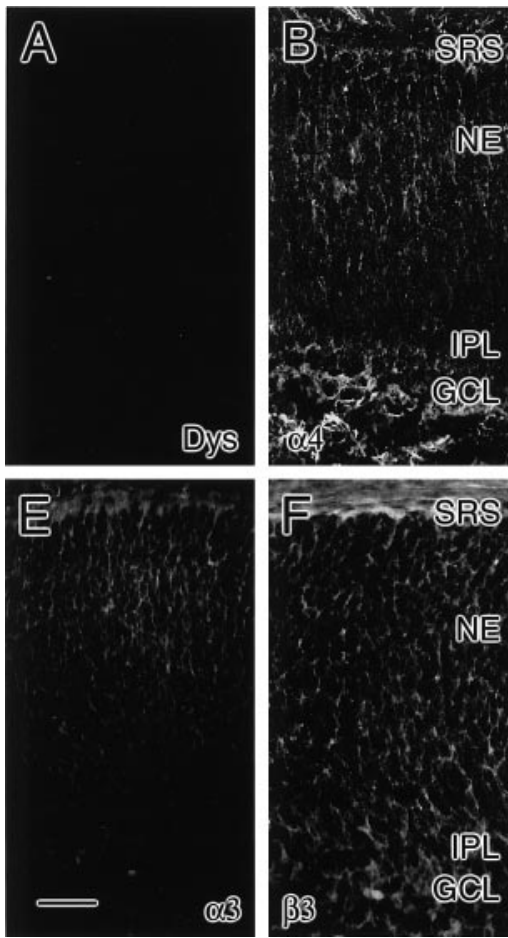
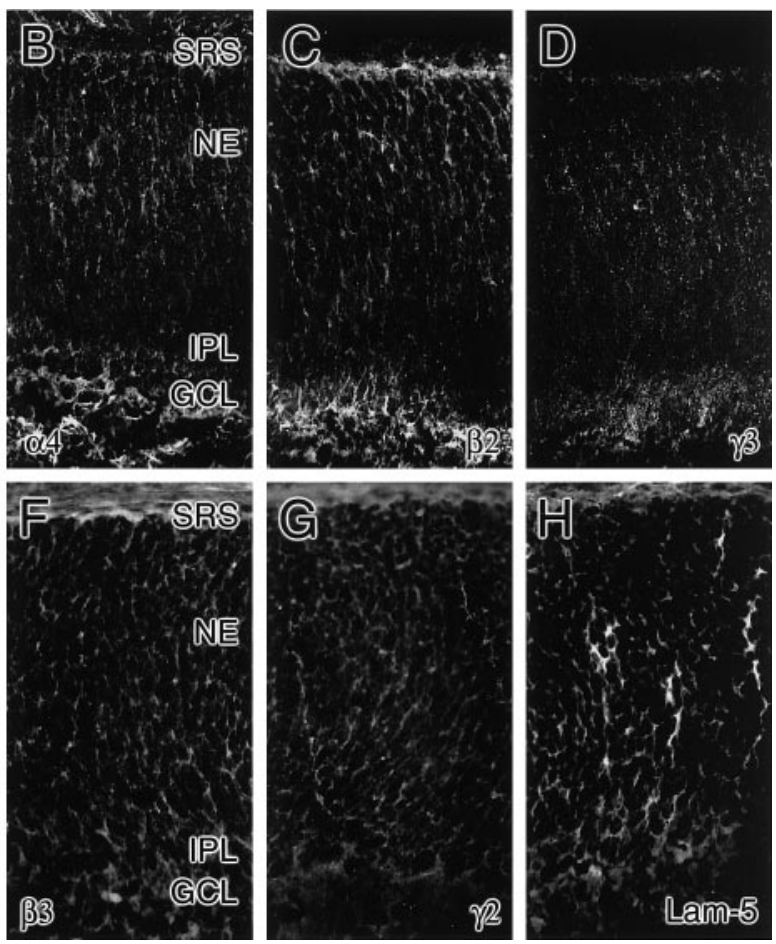

Figure 8. Expression patterns of laminin chains in $\mathrm{P} 0$ rat retina. At PO, the outer plexiform layer has not yet formed, as demonstrated by the lack of dystrophin $(D y s)$ expression in the retina $(A)$. However, the laminin $\alpha 4(B), \beta 2(C)$, and $\gamma 3(D)$ chains are prominently expressed in the subretinal space (SRS) and in fibers spanning the neuroepithelium $(N E)$ and penetrating through the inner plexiform layer $(I P L)$ and ganglion cell layer $(G C L)$. In addition, the components of laminin 5-the $\alpha 3(E), \beta 3(F)$, and $\gamma 2(G)$ chains-are expressed at $\mathrm{P} 0$, as $\mu \mathrm{m}$. 

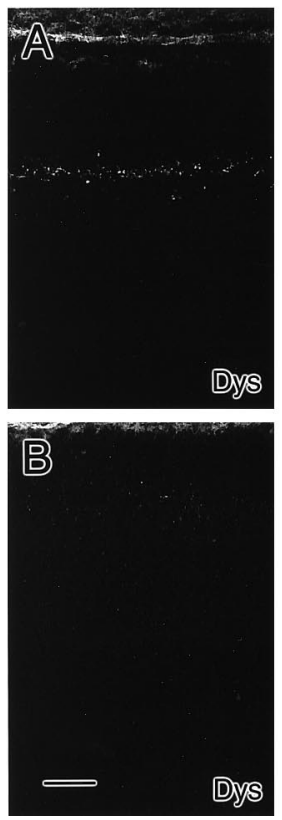
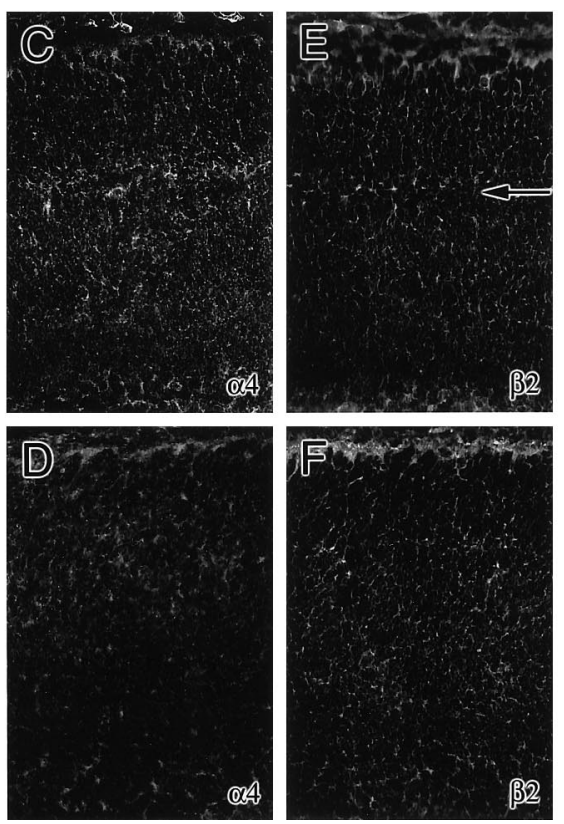
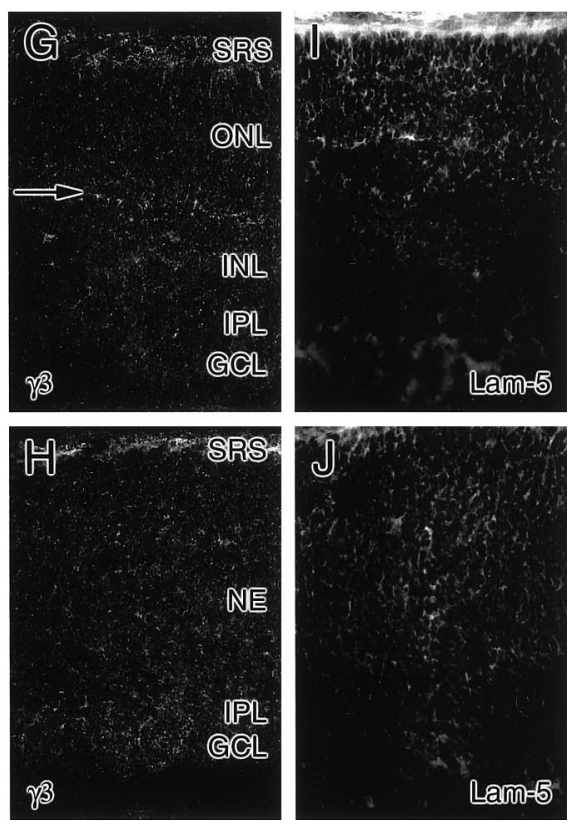

Figure 9. Expression patterns of laminin chains in central (top row; $A, C, E, G, I$ ) and peripheral (bottom row; $B, D, F, H, J$ ) P5 rat retina. At P5, the outer plexiform layer has begun to form in the central retina, as judged by dystrophin $(D y s)$ expression $(A)$, whereas it has not yet formed in the peripheral retina, as demonstrated by the lack of dystrophin expression $(B)$. The laminin $\alpha 4(C, D), \beta 2(E, F)$, and $\gamma 3(G, H)$ chains are expressed in the subretinal space $(S R S)$ and in fibers spanning, centrally, the outer nuclear layer $(O N L)$ and inner nuclear layer (INL) and, peripherally, the neuroepithelium $(N E)$. These fibers penetrate through the inner plexiform layer $(I P L)$ and ganglion cell layer $(G C L)$. All three chains are also present in the developing outer plexiform layer (arrows). In addition, immunoreactivity for laminin 5 (Lam-5) is present at P5 (I, J). Scale bar, $25 \mu \mathrm{m}$.
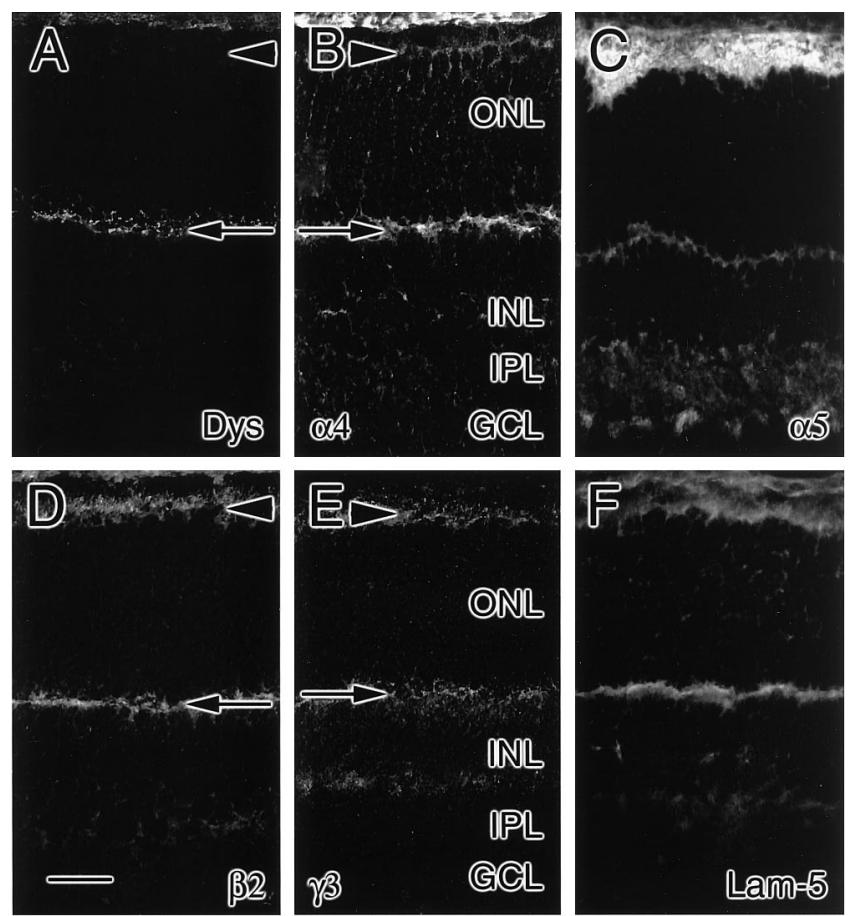

Figure 10. Expression patterns of laminin chains in $\mathrm{P} 10$ rat retina. At P10, the outer plexiform layer has formed throughout the retina, as judged by dystrophin $(D y s)$ expression $(A)$. The laminin $\alpha 4(B), \alpha 5(C), \beta 2(D)$, and $\gamma 3(E)$ chains are expressed most prominently in the interphotoreceptor matrix (arrowheads) and outer plexiform layer (arrows) and are weakly present in fibers spanning the outer nuclear layer $(O N L)$ and inner nuclear layer $(I N L)$; these fibers penetrate through the inner plexiform layer $(I P L)$ and ganglion cell layer $(G C L)$. In addition, laminin 5 (Lam-5) immunoreactivity is present at $\mathrm{P} 10(F)$. Scale bar, $25 \mu \mathrm{m}$.
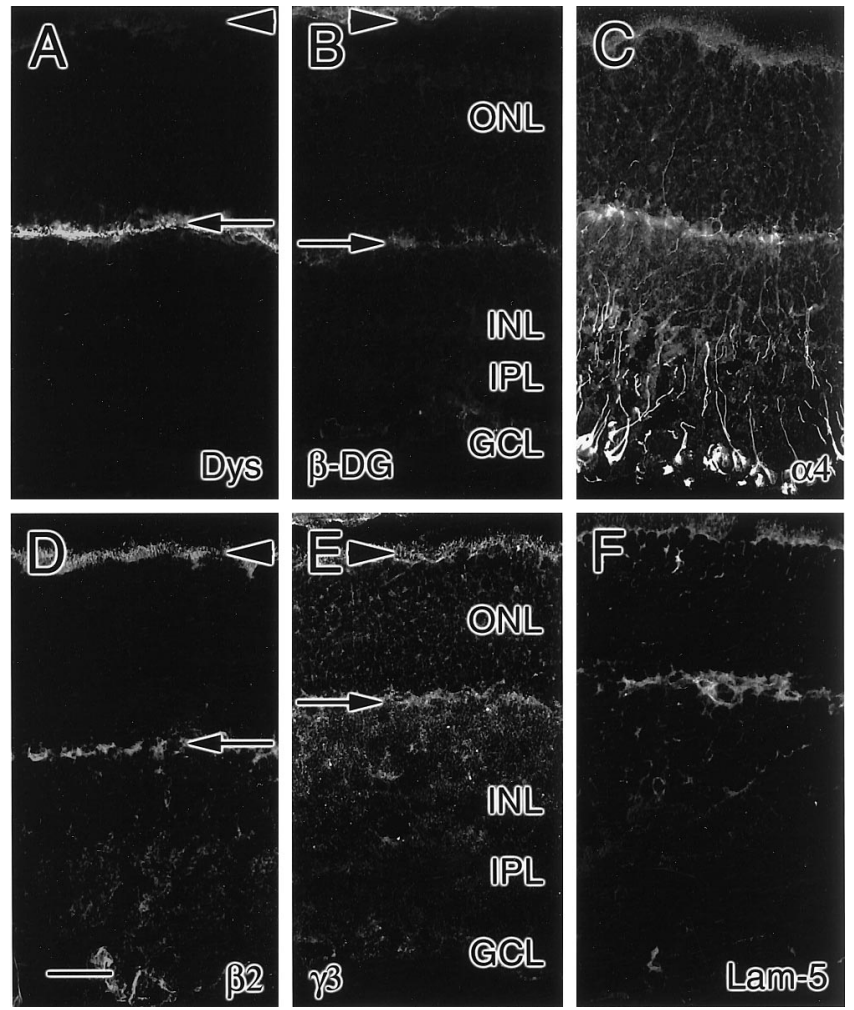

Figure 11. Expression patterns of laminin chains in $\mathrm{P} 15$ rat retina. At $\mathrm{P} 15$ the outer plexiform layer not only contains dystrophin $(D y s ; A)$ but has also started to contain $\beta$-dystroglycan $(\beta-D G ; B)$. The laminin $\alpha 4(C), \beta 2(D)$, and $\gamma 3(E)$ chains are expressed most prominently in the interphotoreceptor matrix (arrowheads) and outer plexiform layer (arrows); in addition, the $\alpha 4$ chain is prominent in fibers spanning the outer nuclear layer $(O N L)$, inner nuclear layer $(I N L)$, inner plexiform layer $(I P L)$, and ganglion cell layer $(G C L)$. In addition, laminin 5 (Lam-5) immunoreactivity remains at P15 $(F)$. Scale bar, $25 \mu \mathrm{m}$. 


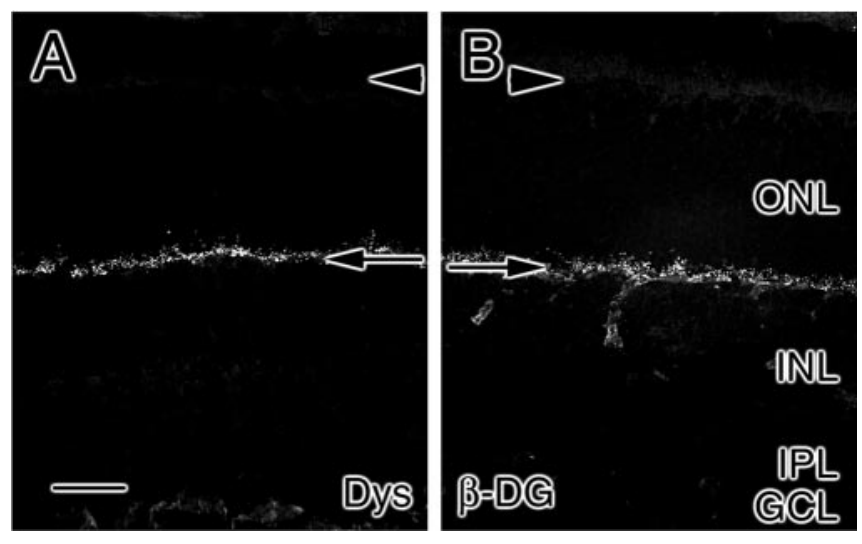

Figure 12. Expression patterns of components of the dystrophin complex in P26 rat retina. At P26, the outer plexiform layer (arrows) not only contains dystrophin $(D y s ; A)$ but also $\beta$-dystroglycan $(\beta-D G ; B)$. In this regard, unlike the $\mathrm{P} 15$ retina, the outer plexiform layer resembles that in the mature retina. GCL, Ganglion cell layer; $I N L$, inner nuclear layer; $I P L$, inner plexiform layer; $O N L$, outer nuclear layer; arrowheads, interphotoreceptor matrix. Scale bar, $25 \mu \mathrm{m}$.

synapse, $\beta$-dystroglycan, is not detectable at this age (data not shown). The components of laminins 14 and 15 (the $\alpha 4, \alpha 5, \beta 2$, and $\gamma 3$ chains; Fig. $10 B-E$ ) are concentrated in the developing interphotoreceptor matrix and the outer plexiform layer; in addition, laminin 5 immunoreactivity remains associated with the subretinal space and the outer plexiform layer (Fig. 10). In addition, monoclonal antibodies against all three chains of lami$\operatorname{nin} 5(\alpha 3, \beta 3$, and $\gamma 2)$ are reactive (data not shown), suggesting that laminin 5 expression continues.

At P15, the outer plexiform layer is beginning to reach maturity, as judged by the continued presence of dystrophins and now detectable levels of $\beta$-dystroglycan (Fig. 11). In other respects, the retina at P15 is similar to that of the adult: the components of laminins 14 and 15 , including the laminin $\alpha 4, \beta 2$, and $\gamma 3$ chains, are prominently expressed in the interphotoreceptor matrix and outer plexiform layer, the $\alpha 4$ chain is prominent in fibers spanning the retina, and laminin 5 remains (Fig. 11). Expression of one component of the outer plexiform layer, $\beta$-dystroglycan, appears to lag behind the others; by P26, however, the expression closely mimics that of the adult (Fig. 12).

In summary, the developing retina contains components of laminins 14 and 15 throughout the period of interphotoreceptor matrix and outer plexiform layer formation. Initially, these chains are expressed in the subretinal space and in fibers spanning the thickness of the retina; with time, they become more restricted to the interphotoreceptor matrix and outer plexiform layer, reflecting the distribution present in the adult. In addition, components of laminin 5 are expressed in the interphotoreceptor matrix and outer plexiform layer of the developing retina but become somewhat restricted to the interphotoreceptor matrix by the time a mature morphology is attained. Remarkably, one component of the putative laminin-binding dystrophin complex, $\beta$-dystroglycan, is expressed relatively late in retinal synaptogenesis, well after the dystrophins and laminins.

\section{DISCUSSION}

\section{Laminins in the IPM and retinal synaptic layers}

We have provided evidence previously that the laminin $\beta 2$ chain is a component of the IPM of adult vertebrate retinae (Hunter et al., 1992b; Libby et al., 1996, 1997). Histologically, the $\beta 2$ chain fills the space between the photoreceptors-the IPM-in en face sections of adult retinae. Biochemically, the $\beta 2$ chain is tightly associated with a matrix fraction of the adult retina, suggesting that it is a component of the IPM. Our immunohistochemical studies reported here, on rat and human retina, show several other laminin chains- $\alpha 3, \alpha 4, \alpha 5, \beta 3, \gamma 2$, and $\gamma 3$-surrounding inner segments, a distribution that is likely to reflect a location in the IPM.

In the IPM, we propose that laminins may be important in maintaining the proper mature environment for photoreceptors. The most obvious role for laminins in the IPM, because laminins are known to be involved in adhesion (Terranova et al., 1983) and the IPM is thought to be important in retinal adhesion (Marmor, 1993), is in retinal adhesion. This is particularly likely for laminin 5 , shown previously to be critical for dermal adhesion. We have shown photoreceptors can adhere to recombinant laminin $\beta 2$ chain (Hunter et al., 1992b). It will now be possible to determine whether the heterotrimeric laminins in the IPM are involved in photoreceptor adhesion.

Several laminin chains are also present in the mature plexiform layers; in particular, the laminin $\alpha 3, \alpha 4, \alpha 5, \beta 2$, and $\gamma 3$ chains are expressed in the outer plexiform layer in a location not likely to be associated with the vasculature. The exact location of the laminin chains in the retinal synaptic layers awaits immunohistochemistry done at the electron microscopic level.

\section{Müller cells produce retinal laminins}

The RNA encoding the laminin chains that are expressed in the mature neural retina is located in cells that span the retina. This location is consistent with the production of laminins by Müller cells (Libby et al., 1997). Müller cell cytoplasm is spread across the retina (Rasmussen, 1972), and RNA is distributed throughout these processes (Sarthy et al., 1989; Erickson et al., 1992). In addition, we have shown that the distribution of the RNA encoding CRALBP, in both rat and human retina (Libby et al., 1997) (see Results), is similar to that of the laminins: throughout the retina, in fibers coursing through the retinal cell layers. Together with the immunohistochemical data noted above, these data support a Müller cell source for laminins in the IPM and synaptic layers.

\section{Laminins in the nervous system}

In the peripheral nervous system, several cell types produce a variety of laminins. For example, the glial elements that wrap peripheral nerves, Schwann cells, have long been known to produce laminins (Cornbrooks et al., 1983; Palm and Furcht, 1983), including at least one that contains the $\beta 2$ chain (Chiu et al., 1991). Conversely, laminins are thought to be important during Schwann cell differentiation (Anton et al., 1994; Fernandez-Valle et al., 1994; Obremski and Bunge, 1995). Also in the periphery, muscle cells appear to express several different laminin trimers on their surface (Hunter et al., 1989; Sanes et al., 1990a,b; Miner et al., 1997; Sorokin et al., 1997), which are likely to be important in guiding innervating motor neurons to their synaptic targets in the muscle, as well as in stabilizing the synapse (Hunter et al., 1989; Noakes et al., 1995). Importantly, one laminin chain, $\alpha 2$, has been shown to be involved in muscular dystrophies: mutations in $\alpha 2$ have been found in murine muscular dystrophies (Xu et al., 1994; Sunada et al., 1995 ) and in some cases of a human congenital muscular dystrophy (Helbling-Leclerc et al., 1995).

Similarly, in the CNS, laminins are present in a variety of areas, particularly during development. The cellular sources of their component chains include all three major cell classes of the CNS: glia, neurons, and neuroglial progenitors. Glial cells, including astrocytes, Bergmann glia, and Müller cells, are thought to be a major source of laminins in the adult and developing CNS (see Liesi et al., 1983, 1995; Liesi, 1985; Liesi and Risteli, 1989; Chiu et al., 1991; Green et al., 1992; Hunter et al., 1992a; Libby et al., 1997; Raabe et al., 1997). Neurons may also produce laminins (Sarthy and Fu, 1990; Suzuki et al., 1990; Morissette and Carbonetto, 1995). Finally, we have shown that the retinal neuroglial progenitor may be a source of laminins during development (Libby et al., 1997).

The ability of all of the major neural cell types of the CNS to produce laminins is consistent with the profusion of roles that have been proposed for laminins in the CNS. Most notably, as with laminins in the peripheral nervous system, laminins in the CNS are 


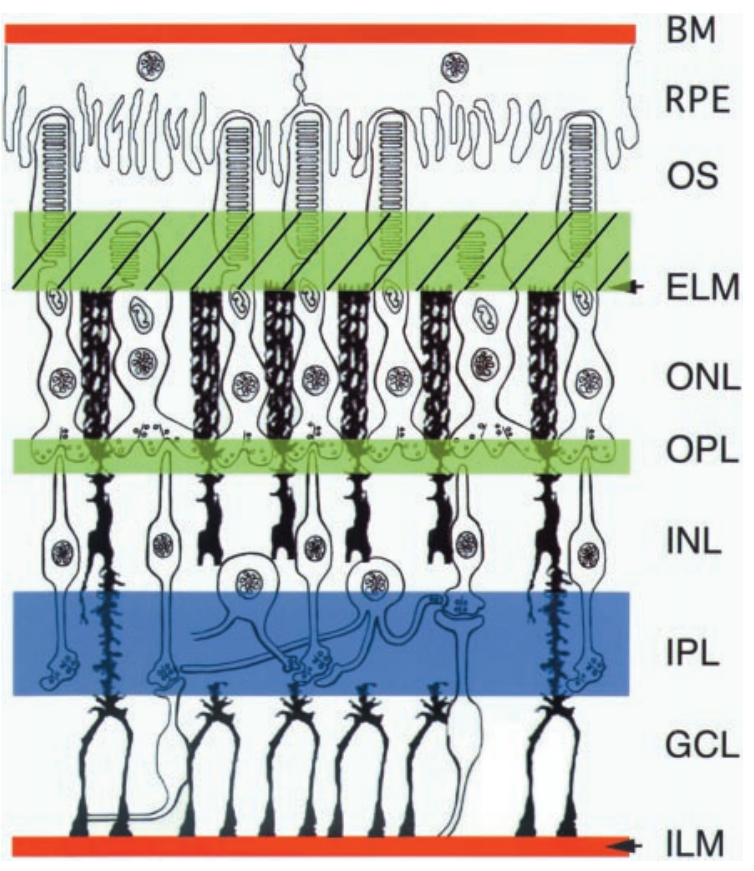

Figure 13. Summary of laminin expression in the retina. At least three distinct laminin compartments are present in the retina: the basement membranes, the interphotoreceptor matrix, and the matrices of the outer plexiform layer $(O P L)$ and of the inner plexiform layer $(I P L)$. Retinal basement membranes, that is, vitreal and Bruch's membranes (red lines), contain the laminin $\alpha 1, \alpha 5, \beta 1, \beta 2$, and $\gamma 1$ chains; the exact composition of laminin isoforms in these membranes awaits the isolation of native laminins from this compartment. The interphotoreceptor matrix (and, during early development, the subretinal space) has a different complement of laminins (green shading/hatched); it contains the laminin $\alpha 3, \alpha 4, \alpha 5, \beta 2, \beta 3, \gamma 2$, and $\gamma 3$ chains. This suggests the presence of three laminins: laminin $5(\alpha 3 \beta 3 \gamma 2)$, isolated previously from other tissues, and laminin $14(\alpha 4 \beta 2 \gamma 3)$ and laminin $15(\alpha 5 \beta 2 \gamma 3)$, newly isolated here (Fig. 7). These same laminin chains are expressed in the outer plexiform layer as it develops; this expression becomes restricted to the $\alpha 3, \alpha 4, \alpha 5, \beta 2$, and $\gamma 3$ chains in the adult (green shading). The matrix of the inner plexiform layer (blue shading), on the other hand, contains only the $\alpha 4$ chain and no other known laminin chains, suggesting the presence of at least two as-yet-identified laminin chains that would partner with the $\alpha 4$ chain to form heterotrimeric laminins in the inner plexiform layer. $B M$, Bruch's membrane; $R P E$, retinal pigmented epithelium; $O S$, outer segments, $E L M$, external limiting membrane; GCL, ganglion cell layer; ILM, internal limiting membrane; INL, inner nuclear layer; $O N L$, outer nuclear layer.

thought to be involved with axon outgrowth, on the basis of the laminins' known roles in axon outgrowth in vitro (for review, see Sanes, 1989; Liesi, 1990) and their distribution along many developing pathways (see Cohen et al., 1987; Liesi and Silver, 1988; Zhou, 1990; Morissette and Carbonetto, 1995). Laminins are also thought to be involved with neuronal differentiation in the CNS; for example, we have shown that retinal laminins containing the $\beta 2$ chain can promote rod photoreceptor differentiation in vitro (Hunter et al., 1992b; Hunter and Brunken, 1997). In addition, we have shown that $\beta 2$ chain-containing laminins are vital during the differentiation of photoreceptors and their synapses in vivo (Libby et al., 1999).

\section{Novel laminin trimers in the CNS}

Here, for the first time, a component of the CNS has been examined for the presence of all the known laminin chains. We summarize our data in Figure 13. Retinal basement membranes contain the laminin $\alpha 1, \alpha 5, \beta 1, \beta 2$, and $\gamma 1$ chains. In contrast, the neural retina has a different complement of at least seven laminin chains: $\alpha 3, \alpha 4, \alpha 5, \beta 2, \beta 3, \gamma 2$, and $\gamma 3$. Of these, it is probable that the $\alpha 3$, $\beta 3$, and $\gamma 2$ chains assemble to form laminin 5 , although we have not purified laminin 5 from retinal extracts. However, together with our biochemical data, our expression data suggest that there are at least two novel laminin trimers-laminin $14(\alpha 4 \beta 2 \gamma 3)$ and laminin $15(\alpha 5 \beta 2 \gamma 3)$-in the CNS. The apparent loss of the $\beta 3$ chain in the adult outer plexiform layer suggests that there could be an additional novel laminin present, laminin $13(\alpha 3 \beta 2 \gamma 3)$, although we have been unable to demonstrate its presence biochemically.

Intriguingly, laminins 14 and 15 appear to be expressed in two locations: (1) within the interphotoreceptor matrix and (2) in the outer plexiform layer (Fig. 13). The location of these laminins in the outer plexiform layer suggests that they may serve to stabilize retinal synapses, in a manner analogous to that suggested for $\beta 2$-containing laminins, perhaps including laminin 11, at the neuromuscular junction (Noakes et al., 1995; Miner et al., 1997). Indeed, we have shown that mice lacking the laminin $\beta 2$ chain have poorly formed and improperly functioning synaptic connections (Libby et al., 1999), suggesting that laminins containing the $\beta 2$ chain are involved in the stabilization of synapses in the CNS. Therefore, laminins 14 and 15 are the first laminins that could be involved in formation or stabilization of synapses within the CNS. Moreover, we have shown that these laminins are present at the same location as two components of the dystrophin complexdystrophins and $\beta$-dystroglycan. Others have reported that dystrophin complexes are present without associated laminins in the retina (Montanaro et al., 1995). Our ability to examine the presence of all known laminin chains has allowed us to demonstrate that laminins are, in fact, associated with dystrophin complexes at central synapses, just as they are at the neuromuscular junction. However, because laminin expression precedes that of one component of the dystrophin complex ( $\beta$-dystroglycan), it seems likely that it is not necessary to assemble the entire complex to stabilize laminins at the photoreceptor synapse.

Our data describing the presence of laminin 5 during development suggest that this trimer may also be involved in retinal differentiation. These data, along with our data that suggest the presence of laminins 14 and 15 during development, support our hypothesis that laminins are critical components of the extracellular environment during differentiation of the nervous system.

There is now an abundance of different laminin chains and the possibility of yet more to be discovered. Of these, at least 10 are expressed in various parts of the adult and developing retina $[\alpha 2$ (Morissette and Carbonetto, 1995); $\alpha 3, \alpha 4$, and $\alpha 5$ (see Results); $\beta 1$ (Sarthy and Fu, 1990); $\beta 1$ and $\gamma 1$ (Dong and Chung, 1991); $\beta 2$ (Hunter et al., 1992b; Libby et al., 1996, 1997); $\beta 3$ (see Results); and $\gamma 2$ and $\gamma 3$ (see Results)]. By extension, we hypothesize that laminins may be ubiquitous in the vertebrate nervous system. In this regard, it will be important to define the laminin trimers that are associated with the nervous system, their receptors, and the functions they may subserve in the developing and adult brain.

\section{REFERENCES}

Anton ES, Sandrock Jr AW, Matthew WD (1994) Merosin promotes neurite growth and Schwann cell migration in vitro and nerve regeneration in vivo: evidence using an antibody to merosin, ARM-1. Dev Biol 164:133-146.

Arahata K, Ishii H, Hayashi YK (1995) Congenital muscular dystrophies. Curr Opin Neurol 8:385-390.

Bunt-Milam AH, Saari JC (1983) Immunocytochemical localization of two retinoid-binding proteins in vertebrate retina. J Cell Biol 97:703-712.

Burgeson RE, Chiquet M, Deutzmann R, Ekblom P, Engel J, Kleinman H, Martin GR, Meneguzzi G, Paulsson M, Sanes J, Timpl R, Tryggvason K, Yamada Y, Yurchenco PD (1994) A new nomenclature for the laminins. Matrix Biol 14:209-211.

Chait BT, Kent SB (1992) Weighing naked proteins: practical, highaccuracy mass measurement of peptides and proteins. Science 257:1885-1894.

Chiu AY, Espinosa de los Monteros A, Cole RA, Loera S, de Vellis J (1991) Laminin and s-laminin are produced and released by astrocytes, Schwann cells, and schwannomas in culture. Glia 4:11-24.

Cohen J, Burne JF, McKinlay C, Winter J (1987) The role of laminin and the laminin/fibronectin receptor complex in the outgrowth of retinal ganglion cell axons. Dev Biol 122:407-418.

Cornbrooks CJ, Carey DJ, McDonald JA, Timpl R, Bunge RP (1983) In vivo and in vitro observations on laminin production by Schwann cells. Proc Natl Acad Sci USA 80:3850-3854.

Dong LJ, Chung AE (1991) The expression of the genes for entactin, laminin A, laminin B1 and laminin B2 in murine lens morphogenesis and eye development. Differentiation 48:157-172.

Engvall E, Davis GE, Dickerson K, Ruoslahti E, Varon S, Manthorpe M (1986) Mapping of domains in human laminin using monoclonal anti- 
bodies: localization of the neurite-promoting site. $\mathrm{J}$ Cell Biol 103:2457-2465.

Erickson PA, Feinstein SC, Lewis GP, Fisher SK (1992) Glial fibrillary acidic protein and its mRNA: ultrastructural detection and determination of changes after CNS injury. J Struct Biol 108:148-161.

Fernandez-Valle C, Gwynn L, Wood PM, Carbonetto S, Bunge MB (1994) Anti- $\beta 1$ integrin antibody inhibits Schwann cell myelination. J Neurobiol 25:1207-1226.

Green TL, Hunter DD, Chan W, Merlie JP, Sanes JR (1992) Synthesis and assembly of the synaptic cleft protein s-laminin by cultured cells. J Biol Chem 267:2014-2022.

Helbling-Leclerc A, Zhang X, Topaloglu H, Cruaud C, Tesson F, Weissenbach J, Tome FM, Schwartz K, Fardeau M, Tryggvason K, Guicheney $\mathrm{P}$ (1995) Mutations in the laminin $\alpha 2$-chain gene (LAMA2) cause merosin-deficient congenital muscular dystrophy. Nat Genet 11:216-218.

Hunter DD, Brunken WJ (1997) $\beta 2$ laminins modulate neuronal phenotype in the rat retina. Mol Cell Neurosci 10:7-15.

Hunter DD, Shah V, Merlie JP, Sanes JR (1989) A laminin-like adhesive protein concentrated in the synaptic cleft of the neuromuscular junction. Nature 338:229-234.

Hunter DD, Llinas R, Ard M, Merlie JP, Sanes JR (1992a) Expression of s-laminin and laminin in the developing rat central nervous system. J Comp Neurol 323:238-251.

Hunter DD, Murphy MD, Olsson CV, Brunken WJ (1992b) S-laminin expression in adult and developing retinae: a potential cue for photoreceptor morphogenesis. Neuron 8:399-413.

Kallunki P, Sainio K, Eddy R, Byers M, Kallunki T, Sariola J, Beck K, Jirvonen J, Shows TB, Tryggvason K (1992) A truncated laminin chain homologous to the B2 chain: structure, spatial expression, and chromosomal assignment. J Cell Biol 119:679-693.

Koch M, Olson PF, Albus A, Jin W, Hunter DD, Brunken WJ, Burgeson RE, Champliaud MF (1999) Characterization and expression of the laminin $\gamma 3$ chain: a novel, non-basement membrane-associated, laminin chain. J Cell Biol 145:605-618.

Kohno T, Sorgente N, Ishibashi T, Goodnight R, Ryan SJ (1987) Immunofluorescent studies of fibronectin and laminin in the human eye. Invest Ophthalmol Vis Sci 28:506-514.

Laemmli UK (1970) Cleavage of structural proteins during the assembly of the head of bacteriophage T4. Nature 227:680-685.

Libby RT, Hunter DD, Brunken WJ (1996) Developmental expression of laminin $\beta 2$ in rat retina. Further support for a role in rod morphogenesis. Invest Ophthalmol Vis Sci 37:1651-1661.

Libby RT, Xu Y, Selfors LM, Brunken WJ, Hunter DD (1997) Identification of the cellular source of laminin $\beta 2$ in adult and developing vertebrate retinae. J Comp Neurol 389:355-367.

Libby RT, Lavalle C, Balkema GW, Brunken WJ, Hunter DD (1999) Disruption of laminin $\beta 2$ chain production causes alterations in morphology and function in the CNS. J Neurosci 19:9399-9411.

Liesi P (1985) Laminin-immunoreactive glia distinguish regenerative adult CNS systems from non-regenerative ones. EMBO J 4:2505-2511.

Liesi P (1990) Extracellular matrix and neuronal movement. Experientia 46:900-907.

Liesi P, Risteli L (1989) Glial cells of mammalian brain produce a variant form of laminin. Exp Neurol 105:86-92.

Liesi P, Silver J (1988) Is astrocyte laminin involved in axon guidance in the mammalian CNS? Dev Biol 130:774-785.

Liesi P, Dahl D, Vaheri A (1983) Laminin is produced by early rat astrocytes in primary culture. J Cell Biol 96:920-924.

Liesi P, Hager G, Dodt HU, Seppala I, Zieglgansberger W (1995) Domain-specific antibodies against the B2 chain of laminin inhibit neuronal migration in the neonatal rat cerebellum. $J$ Neurosci Res 40:199-206

Marinkovich MP, Lunstrum GP, Burgeson RE (1992) The anchoring filament protein kalinin is synthesized and secreted as a high molecular weight precursor. J Biol Chem 267:17900-17906.

Marmor MF (1993) Mechanisms of retinal adhesion. In: Progress in retinal research (Osborne NN, Chader GJ, eds), pp 179-204. New York: Pergamon.

Miner JH, Lewis RM, Sanes JR (1995) Molecular cloning of a novel laminin chain, $\alpha 5$, and widespread expression in adult mouse tissues. J Biol Chem 270:28523-28526.

Miner JH, Patton BL, Lentz SI, Gilbert DJ, Snider WD, Jenkins NA, Copeland NG, Sanes JR (1997) The laminin alpha chains: expression, developmental transitions, and chromosomal locations of $\alpha 1-5$, identification of heterotrimeric laminins $8-11$, and cloning of a novel $\alpha 3$ isoform. J Cell Biol 137:685-701.

Montanaro F, Carbonetto S, Campbell KP, Lindenbaum M (1995) Dystroglycan expression in the wild type and $\mathrm{mdx}$ mouse neural retina: synaptic colocalization with dystrophin, dystrophin-related protein but not laminin. J Neurosci Res 42:528-538.

Morissette N, Carbonetto S (1995) Laminin $\alpha 2$ chain (M chain) is found within the pathway of avian and murine retinal projections. J Neurosci 15:8067-8082.

Noakes PG, Gautam M, Mudd J, Sanes JR, Merlie JP (1995) Aberrant differentiation of neuromuscular junctions in mice lacking s-laminin/ laminin $\beta 2$. Nature 374:258-262.

Obremski VJ, Bunge MB (1995) Addition of purified basal lamina molecules enables Schwann cell ensheathment of sympathetic neurites in culture. Dev Biol 168:124-137.

Palm SL, Furcht LT (1983) Production of laminin and fibronectin by Schwannoma cells: cell-protein interactions in vitro and protein localization in peripheral nerve in vivo. J Cell Biol 96:1218-1226.

Raabe EH, Yoshida K, Schwarting GA (1997) Differential laminin isoform expression in the developing rat olfactory system. Dev Brain Res 101:187-196.

Rasmussen KE (1972) A morphometric study of the Müller cell cytoplasm in the rat retina. $\mathrm{J}$ Ultrastruct Res 39:413-429.

Rouselle P, Lunstrum GP, Keene DR, Burgeson RE (1991) Kalinin: an epithelium-specific basement membrane adhesion molecule that is a component of anchoring filaments. J Cell Biol 114:567-576.

Ryan MC, Christiano AM, Engvall E, Wewer UM, Miner JH, Sanes JR, Burgeson RE (1996) The functions of laminins: lessons from in vivo studies. Matrix Biol 15:369-381.

Sanes JR (1989) Extracellular matrix molecules that influence neural development. Annu Rev Neurosci 12:491-516.

Sanes JR, Chiu AY (1983) The basal lamina of the neuromuscular junction. Cold Spring Harb Symp Quant Biol 48:667-678.

Sanes JR, Engvall E, Butkowski R, Hunter DD (1990a) Molecular heterogeneity of basal laminae: isoforms of laminin and collagen IV at the neuromuscular junction and elsewhere. J Cell Biol 111:1685-1699.

Sanes JR, Hunter DD, Green TL, Merlie JP (1990b) S-laminin. Cold Spring Harb Symp Quant Biol 55:419-430.

Sarthy PV, Fu M (1990) Localization of laminin B1 mRNA in retinal ganglion cells by in situ hybridization. J Cell Biol 110:2099-2108.

Sarthy PV, Fu M, Huang J (1989) Subcellular localization of an intermediate filament protein and its mRNA in glial cells. Mol Cell Biol 9:4556-4559.

Sarthy V (1993) Collagen IV mRNA expression during development of the mouse retina: an in situ hybridization study. Invest Ophthalmol Vis Sci 34:145-152.

Sorokin LM, Pausch F, Frieser M, Kroger S, Ohage E, Deutzmann R (1997) Developmental regulation of the laminin $\alpha 5$ chain suggests a role in epithelial and endothelial cell maturation. Dev Biol 189:285-300.

Sugiyama S, Utani A, Yamada S, Kozak CA, Yamada Y (1995) Cloning and expression of the mouse laminin $\gamma 2(\mathrm{~B} 2 \mathrm{t})$ chain, a subunit of epithelial cell laminin. Eur J Biochem 228:120-128.

Sunada Y, Bernier SM, Utani A, Yamada Y, Campbell KP (1995) Identification of a novel mutant transcript of laminin $\alpha 2$ chain gene responsible for muscular dystrophy and dysmyelination in dy2 J mice. Hum Mol Genet 4:1055-1061.

Suzuki H, Yamamoto T, Yamamoto H, Konno H, Iwasaki Y, Ohara Y Terunuma H (1990) Intraneuronal laminin-like immunoreactivity in the human central nervous system. Brain Res 520:324-329.

Terranova VP, Rao CN, Kalebic T, Margulies IM, Liotta LA (1983) Laminin receptor on human breast carcinoma cells. Proc Natl Acad Sci USA 80:444-448.

Tiger CF, Champliaud MF, Pedrosa-Domellof F, Thornell LE, Ekblom P, Gullberg D (1997) Presence of laminin $\alpha 5$ chain and lack of laminin $\alpha 1$ chain during human muscle development and in muscular dystrophies. J Biol Chem 272:28590-28595.

Timpl R (1996) Macromolecular organization of basement membranes. Curr Opin Cell Biol 8:618-624.

Toti P, De Felice C, Malandrini A, Megha T, Cardone C, Villanova M (1997) Localization of laminin chains in the human retina: possible implications for congenital muscular dystrophy associated with $\alpha 2$-chain of laminin deficiency. Neuromuscul Disord 7:21-25.

Towbin H, Staehelin T, Gordon J (1979) Electrophoretic transfer of proteins from polyacrylamide gels to nitrocellulose sheets: procedure and some applications. Proc Natl Acad Sci USA 76:4350-4354.

Utani A, Kopp JB, Kozak CA, Matsuki Y, Amizuka N, Sugiyama S, Yamada Y (1995) Mouse Kalinin B1 (laminin $\beta 3$ chain): cloning and tissue distribution. Lab Invest 72:300-310.

Wewer UM, Durkin ME, Zhang X, Laursen H, Nielsen NH, Towfighi J, Engvall E, Albrechtsen R (1995) Laminin $\beta 2$ chain and adhalin deficiency in the skeletal muscle of Walker-Warburg syndrome (cerebroocular dysplasia-muscular dystrophy). Neurology 45:2099-2101.

Xu H, Wu XR, Wewer UM, Engvall E (1994) Murine muscular dystrophy caused by a mutation in the laminin $\alpha 2$ (Lama2) gene. Nat Genet 8:297-302

Zhou FC (1990) Four patterns of laminin-immunoreactive structure in developing rat brain. Brain Res Dev Brain Res 55:191-201. 